\title{
1. ALGUNOS ASPECTOS DEL RÉGIMEN JURÍDICO DE LA PRENSA *
}

\author{
ENRIQUE ÁLVAREZ CONDE \\ Catedrático de Derecho Constitucional \\ Universidad de Valencia
}

* Este trabajo que coincide sustancialmente con la voz «Prensa» que aparecerá en la Enciclopedia Jurídica Seix, no hubiera podido ser realizado sin las aportaciones, cientificas y documentales, facilitadas, en su día, por los profesores Carlos Soria y Javier Garcia Fernández. A ambos, mi más sincero agradecimiento. Con posterioridad a la finalización del mismo - febrero de 1991-el Tribunal Constitucional ha pronunciado diferentes sentencias, entre ellas las 197/91, de 17 de octubre, relativa al caso SARA MONTIEL, y 214/91, de 11 de noviembre, referente al caso VIOLETA FRIEDMAN, que parecen suponer un cambio radical en su orientación jurisprudencial, nada deseable por cierto. Razones de imprenta han impedido un comentario pormenorizado de las mismas. 


\section{SUMARIO}

I. INTRODUCCIÓN.-II. LA LIBERTAD DE EXPRESIÓN Y EL DERECHO A LA INFORMACIÓN.-a) Naturaleza. b) Relaciones. c) Contenido. III. LA PRensa en el CONSTITUCionalismo histórico español Y EN EL DERECHO COMPARADO.-a) El Constitucionalismo histórico español. b) La Prensa en el Derecho Comparado. c) La regulación internacional de la libertad de Prensa. IV. EL RÉGIMEN JURIDICO DE LA PRENSA EN ESPAÑA.-a) Introducción. b) La vigencia de la Ley de Prensa e Imprenta de 1966. V. EL CONTENIDO DE LA LIBERTAD DE PRENSA.-a) Los sujetos de la información. b) El objeto de la información. c) La regulación de los medios informativos. d) Las ayudas a la Prensa. VI. LAS GARANTIAS DE LA LIBERTAD DE PRENSA.-a) Introducción. b) Garantías de orden civil. c) Garantías de orden penal. 
Revista de Derecho Político, núm. 34, 1991, pp. 11-70

\title{
1. ALGUNOS ASPECTOS DEL RÉGIMEN JURÍDICO DE LA PRENSA
}

\author{
POR \\ ENRIQUE ÁLVAREZ CONDE \\ Catedrático de Derecho Constitucional \\ Universidad de Valencia
}

\section{INTRODUCCIÓN}

El tema de la conceptualización de los derechos fundamentales y libertades públicas constitucionalizados en nuestra Norma Fundamental, y entre ellos los reconocidos en el artículo 20, presenta importantes problemas que hacen necesario acudir a un proceso de conceptualización histórica, a lo largo del cual se han ido perfilando determinadas categorías conceptuales. Pensemos, a modo de ejemplo, en la noción de derecho natural, de libertad pública, de derecho subjetivo, de garantía institucional y un largo etcétera?.

Sin entrar en el fondo de esta problemática conceptual, podemos afirmar que hoy día parece adquirir una cierta aceptación la expresión de «Derechos Fundamentales», sin perjuicio de la utilidad de acudir, en determinadas ocasiones, a otras categorías conceptuales, también constitucionalizadas, y a las que se ha referido nuestra propia jurisprudencia constitucional. Pero lo importante es señalar que la expresión Derechos Fundamentales puede ser delimitada, en nuestro ordenamiento jurídico,

1 Sobre estas cuestiones, cfr., entre otros, A. E. Pérez Luño: Derechos Humanos, Estado de Derecho y Constitución, Tecnos, Madrid 1984; A. TruYol: Los derechos humanos, Tecnos, Madrid 1984; R. SÁnchez Ferriz: Estudio sobre las libertades, Tirant Lo Blanch, Valencia 1989; G. PECES BARBA: Teoría de los Derechos Fundamentales, Guadiana, Madrid 1973; P. Cruz VILLALON: «Formación y evolución de los Derechos Fundamentales", Revista Española de Derecho Constitucional, núm. 25, pp. 35 y ss.; I. DucHAECK: Derechos y libertades en el mundo actual, Instituto de Estudios Políticos, Madrid 1976, etc. 
desde una doble perspectiva. Asi, desde un punto de vista formal, tendrían la consideración de derechos fundamentales aquellos que están dotados de un especial sistema de protección, como pudiera ser el principio de reserva de ley orgánica y el recurso de amparo constitucional. $Y$ desde un punto de vista material, la condición de derechos fundamentales vendría determinada, entre otros, por dos requisitos: Por un lado, sólo tienen esta consideración aquellos derechos subjetivos del ciudadano frente a los poderes públicos, garantizándose de este modo un status jurídico de libertad de la persona, y, por otro, se exigiría además que esos derechos se objetivasen convirtiéndose en valores o elementos configuradores y fundamentadores del propio sistema político. Es decir, se parte de la concepción liberal, que configura a los derechos fundamentales como unos derechos de defensa, pero se acentúa también su carácter institucional, así como su dimensión axiológica, que les conlleva a su condición de elementos transformadores del Estado Social y Democrático de Derecho en que se asienta nuestro sistema político.

Desde este planteamiento, los derechos fundamentales no pueden ser concebidos como una categoria conceptual absoluta, con carácter permanente e inmutable, sino que tienen un significado marcadamente contingente, nunca válido para todo tiempo y lugar.

Esta concepción parece haber presidido la doctrina sentada por nuestra jurisprudencia constitucional. Baste para ello dos muestras importantes. Así, la sentencia de 14 de julio de 1981 afirma: «En primer lugar, los derechos fundamentales son derechos subjetivos, derechos de los individuos, no sólo en cuanto derechos de los ciudadanos en sentido estricto, sino en cuanto garantizan un status jurídico o la libertad de un ámbito de existencia. Pero, al propio tiempo, son elementos esenciales del ordenamiento juridico objetivo de la comunidad nacional, en cuanto ésta se configura como un marco de convivencia humana, justa y pacífica, plasmada históricamente en un Estado de Derecho y, más tarde, en un Estado Social y Democrático de Derecho". Y, en otra ocasión, en la sentencia sobre la despenalización parcial del aborto, de 11 de abril de 1985, reafirma la misma idea al señalar que «los derechos fundamentales no incluyen solamente derechos subjetivos de defensa de los individuos frente al Estado, y garantías institucionales sino también deberes positivos por parte de éste... Además, los derechos fundamentales son los componentes estructurales básicos tanto del conjunto del ordenamiento jurídico objetivo como de cada una de las ramas que lo integran, en razón de que son las expresiones jurídicas de un sistema de valores que, por decisión del constituyente, han de informar la organización jurídica y política». 
Todo este proceso de conceptualización puede ser enfocado desde la perspectiva de las llamadas generaciones de derechos y libertades ${ }^{2}$. A este respecto, se puede hablar de una primera generación, compuesta por los derechos de origen liberal y burgués, que se configurarian como auténticos derechos de defensa del individuo frente a los poderes públicos, tratando de garantizar una esfera de autonomia individual inmune a la acción del poder político del Estado. En segundo lugar, nos encontraríamos con la llamada generación del constitucionalismo socioeconómico, que tiende a garantizar el aspecto subjetivo de los derechos y libertades, en el sentido de configurarlos como auténticos derechos de prestación que generan obligaciones por parte de los poderes públicos. $Y$, finalmente, la tercera generación, los llamados «derechos nuevos», supondria la consagración, a nivel constitucional, de las transformaciones experimentadas por el Estado constitucional de nuestros días. Por lo que se refiere al presente estudio, así como la libertad de expresión es uno de los derechos típicos de la primera generación, el derecho a la información se englobaría, junto a otros también constitucionalizados en nuestra Norma Fundamental, en la tercera.

Ahora bien, este proceso de conceptualización no es tan sencillo como a primera vista pudiera parecer. En efecto, hoy día es muy difícil aceptar, con carácter excluyente, la distinción entre derechos de defensa y derechos de prestación, pues lo normal, como así ha reconocido nuestra propia jurisprudencia, es la coexistencia de ambas calificaciones en todo tipo de derechos y libertades, acentuándose, según los casos, uno u otro carácter.

Por otro lado, también hay que tener en cuenta que con este planteamiento no se trata sino de poner de relieve el constante proceso de actualización de los derechos y libertades, rechazándose las tesis del numerus clausus de los mismos, y proclamando su expansividad, lo cual, por otro lado, no debe conducir a la pérdida de su eficacia jurídica.

Ciertamente, la ampliación de los derechos fundamentales puede realizarse a través de diferentes técnicas. Así, por un lado, nos encontramos con la constitucionalización de los «nuevos derechos», tal y como han hecho las Constituciones recientemente promulgadas, entre ellas la portuguesa y la española. Por otro lado, también se puede proceder a dicha ampliación a través de la ratificación de los correspondientes Tratados y Convenios Internacionales, máxime teniendo en cuenta lo dis-

2 Cfr., a este respecto, el planteamiento que efectúa, entre nosotros, P. LuCAS MURILLO: El derecho a la autodeterminación informativa, Tecnos, Madrid 1990, especialmente pp. 33 y ss. Cfr., asimismo, A. E. PéREZ LuÑo: Los derechos fundamentales, cit., y F. LAPORTA: Sobre el concepto de derechos humanos, Doxa, núm. 4, 1987, así como la bibliografía citada en nota anterior. 
puesto en el artículo 10.2 de la Constitución. Y, finalmente, también es posible proceder por vía interpretativa. Son los llamados derechos fundamentales de configuración jurisprudencial. Pensemos, a modo de ejemplo, en la interpretación que el Tribunal Constitucional español ha realizado del artículo 27.

Ahora bien, este constante proceso de ampliación que, en puridad, conduciría a hablar siempre de nuevas generaciones de derechos y libertades, no es sino una manifestación de la función transformadora de los derechos fundamentales y de las potencialidades insitas en todo texto constitucional democrático.

Sin duda alguna, dentro de esta problemática hay que insertar el complejo contenido del artículo 20 de nuestra Norma Fundamental, donde se constitucionalizan una serie de derechos fundamentales. Nosotros no nos vamos a referir a toda esta problemática sino únicamente a determinados aspectos parciales de los apartados a) y d) (libertad de expresión y derecho a la información), donde debe encardinarse la problemática de la Prensa. Asimismo, hay que tener en cuenta, aunque no reviste un carácter sustancial para nuestro estudio, otras previsiones constitucionales, como son las establecidas en el artículo 149.1.27, norma delimitadora de las competencias entre el Estado y las Comunidades Autónomas en materia de Prensa, y que ha servido de fundamento a nuestra jurisprudencia constitucional para justificar el sistema de ayudas a la Prensa.

\section{LA LIBERTAD DE EXPRESIÓN Y EL DERECHO A LA INFORMACIÓN}

El artículo 20 de la Constitución es un precepto sumamente heterogéneo, donde se contienen una diversidad de derechos y libertades, algunos de los cuales, como es la libertad de cátedra, deberían estar ubicados en otro precepto constitucional, en concreto en el artículo $27^{3}$. Como

3 Sobre la problemática de la libertad de cátedra, cfr. la importante sentencia 5/1981, de 13 de febrero, y, sobre el apartado b) del artículo 20, cfr., entre otros, los Autos 266/1983, de 8 de junio, y 130/1985, de 27 de febrero, así como la sentencia 153/1985, de 7 de noviembre. 
ya apuntábamos, nuestro análisis se va a centrar únicamente en aquellos aspectos que, dentro de la problemática de la libertad de expresión y del derecho a la información ${ }^{4}$, afecten a la Prensa.

Todo ello sin olvidar, como ha señalado la sentencia de 16 de marzo de 1981, que en todos sus apartados se trata de garantizar el derecho a una comunicación pública libre, que es el sustento del sistema democrático: «El artículo 20 de la Constitución, en sus distintos apartados, garantiza el mantenimiento de una comunicación pública libre, sin la cual quedarían vaciados de contenido real otros derechos que la Constitución consagra, reducidas a formas hueras las instituciones representativas y absolutamente falseado el principio de legitimidad democrática que enuncia el artículo 1, apartado 2, de la Constitución, y que es la base de toda nuestra ordenación jurídico-política». Y más adelante añade: «La preservación de esta comunicación pública libre sin la cual no hay sociedad libre ni, por tanto, soberanía popular, exige la garantía de ciertos derechos fundamentales comunes a todos los ciudadanos, y la interdicción con carácter general de determinadas actuaciones del poder..., pero también una especial consideración a los medios que aseguran la comunicación social y, en razón de ello, a quienes profesionalmente la sirven».

En estas palabras se vislumbran ya las ideas fundamentales de nuestra jurisprudencia constitucional en torno a la naturaleza de estos derechos y libertades. Sin embargo, no resulta fácil establecer las líneas o etapas de evolución de su configuración doctrinal, pues éstas son distintas en cada uno de los aspectos que afectan a la libertad de expresión y al derecho a la información y, quizá, todo lo más que pudiera afirmarse es que aún no estamos ante una jurisprudencia constitucional consolidada, manteniéndose constantes flujos y reflujos en su elaboración doctrinal ${ }^{5}$.

4 La bibliografia sobre el articulo 20 es muy numerosa. A modo de ejemplo, cfr. M. FERnÁndez AREAL: Introducción al derecho a la información, Barcelona 1977; M. A. Garcia Herrera: «Estado democrático y libertad de expresión», Revista de la Facultad de Derecho de la Universidad Complutense, núms. 65 y 66; M. SAAVEDRA LópEz: La libertad de expresión en el Estado de Derecho. Entre la utopia y la realidad, Ariel, Barcelona 1987; J. TERRÓN: “Libertad de expresión y Constitución», Documentación Administrativa, núm. 187; R. DUMAS: Le droit de l'information, PUF, Paris 1978; J. M. Desantes: La información como derecho, 1976, y «De la libertad de expresión al derecho a la información», Persona y Derecho, vol. 24, 1991, pp. 23 y ss.; J. DE EsteBAN: Por una comunicación democrática, Valencia 1976; C. SORIA: «El derecho a la información en la Constitución española», en Rev. I/ diritto delle Radiodiffusioni e delle Telecomunicazioni, núm. 2, 1984, pp. 179 y ss., y un larguísimo etcétera.

5 Tampoco nuestra jurisprudencia ordinaria parece haber arrojado grandes luces sobre el tema. Por un lado, las primeras sentencias (STS de 14 de agosto de 1979 y 30 de septiembre de 1980) reconocen su consideración de derechos de libertad. Por otro, las sentencias posteriores se han limitado a reproducir, miméticamente, la jurisprudencia constitucional, no produciéndose siempre, como más 
Por ello, más que hablar de etapas, vamos a referirnos a la postura de nuestra jurisprudencia en determinadas cuestiones puntuales y concretas.

\section{a) Su naturaleza}

La naturaleza de la libertad de expresión y del derecho a la información ha presentado una evolución jurisprudencial cuyos hitos más importantes parecen afectar a dos cuestiones fundamentales: por un lado, su carácter de derechos de libertad y/o derechos de prestación, y, por otro, su carácter de libertades preferentes.

Por lo que se refiere a su condición de derechos de libertad y/o prestación, el primer hito importante se va a producir en la sentencia $6 / 1981$, de 16 de marzo, en la cual se proclama su condición de «derechos de libertad frente al poder y comunes a todos los ciudadanos". Sin embargo, en esta misma decisión jurisprudencial se apunta ya el problema del posible carácter prestacional de los mismos, en base a lo establecido en el artículo 20.3 y, principalmente, debido a su condición de derechos destinados a la garantía de la opinión pública libre. Particularmente significativo resulta, a este respecto, el voto particular del Sr. Fernández Viagas, en el cual se afirma que la libertad de expresión, y más específicamente la libertad de Prensa, además de presentar un aspecto subjetivo, engloba un aspecto institucional, cuya finalidad es la garantía de la opinión pública libre, tendiendo «a realizar, en el plano de la información, el pluralismo politico y que requiere, en este campo concreto, la adscripción de medidas correctoras de la desigualdad..., lo que puede conseguirse mediante el uso ordenado de los medios de comunicación social del Estado".

Esta relación dialéctica entre su consideración como derecho de libertad y derecho de prestación se vuelve a plantear en la importante sentencia 12/1982, de 31 de marzo, sobre el caso "Antena 3", en la cual se afirma contundentemente que estamos en presencia de un derecho de libertad "por to que básicamente significa ausencia de interferencias o de intromisiones de las autoridades estatales en el proceso de comunicación". Pero - añade - también «significa el reconocimiento y la garantía de una institución política fundamental, que es la opinión pública libre, indisolublemente ligada con el pluralismo político que es un valor fundamental y un requisito de funcionamiento del Estado democrático. El artículo 20 defiende la libertad en la formación y en el desarrollo de la opinión pública, pues la libertad en la expresión de las ideas y los pensamientos y en la difusión de noticias es necesaria premisa de la opinión pública libre».

En el fondo de esta tensión dialéctica subyacía el problema de si ambos derechos y libertades comprendían o no el derecho a crear los

adelante veremos, una adecuada interpretación de la legislación penal y civil en relación con los contenidos constitucionales. 
medios necesarios para la difusión de noticias, cuestión que abordaremos cuando analicemos el contenido de estos derechos.

Esta configuración como derechos de libertad, pero sin olvidar su dimensión institucional va a ser reiterada, con mejor o peor acierto, por otras decisiones jurisprudenciales. Entre ellas, habría que mencionar la sentencia 77/1982, de 20 de diciembre, donde se proclama, debido a su condición de derechos de libertad, la innecesariedad de un reconocimiento expreso por parte de los poderes públicos, pues son derechos que nacen de la Constitución. Asimismo, la sentencia 86/1982, de 23 de diciembre, afirma contundentemente que «no son derechos de prestación, sino que se traducen en la libertad que de los mismos se reconocen a los ciudadanos, para cuya efectividad no se requiere constitucionalmente, ni está tampoco prohibido, que existan medios de Prensa dependientes del Estado o de cualquier ente público, al ser éste un tema en el que caben, dentro de la Constitución, diversas opciones políticas". Y es que en el fondo de la sentencia se cuestionaba la constitucionalidad de la Ley 11/1982, de 13 de abril, por la cual se suprimió el organismo autónomo Medios de Comunicación Social del Estado.

Finalmente, habria que mencionar otra serie de decisiones jurisprudenciales, entre las cuales destaca la sentencia 105/1983, de 23 de noviembre, realtiva al caso Vinader, en la cual se proclama su condición de derecho de libertad que "se concreta y satisface en un comportamiento de su titular consistente en la realización de los actos en que el propio derecho consiste y la lesión directa se produce en todos aquellos casos en que tal comportamiento - los actos de comunicación y difusión-se ven impedidos por vía de hecho o por una orden o consignación que suponga un impedimento para que la información sea realizada». Por su parte, el Auto 673/ 1985, de 9 de octubre, proclama su condición de derecho de libertad frente a los poderes públicos «y no un derecho frente a otros individuos, que imponga a éstos el deber de aceptar las afirmaciones vertidas ni les impida extraer de ellas las consecuencias que los mismos puedan producir en las relaciones juridicas entre particulares». Y, finalmente, la sentencia 63/1987, de 20 de mayo, concluye que estamos en presencia de un derecho de libertad que no exige, con carácter general, sino la abstención de los poderes públicos, matizando que «en determinados casos será necesaria la actuación positiva de los poderes públicos para la ordenación de los medios que sirvan de soporte a la expresión y difusión de las ideas".

Así pues, nuestra jurisprudencia constitucional opta claramente por su condición de derechos de libertad, con todas las consecuencias que ello implica, pero no olvida tampoco su dimensión institucional, sin que ello suponga configurarles como auténticos derechos de prestación.

Por lo que se refiere a la segunda cuestión, es decir, a su carácter de derechos o libertades preferentes, nuestra jurisprudencia parece haber aceptado la doctrina acuñada por la jurisprudencia norteamericana de las 
libertades preferentes ${ }^{6}$, aunque tampoco se produce una evolución jurisprudencial continuada y totalmente coherente.

La primera sentencia importante que aborda el problema es la 104/ 1986, de 17 de julio, relativa al caso Soria Semanal, en la cual tras señalar que el derecho al honor es un derecho fundamental y un límite expreso, a tenor de to establecido en el artículo 20.4, establece el principio de que cuando se produce un conflicto de derechos, ambos de rango fundamental, hay que acudir al criterio de la ponderación entre uno y otro. A continuación, tras desechar la idea, que había sido acuñada por nuestra jurisprudencia ordinaria, de que el expreso reconocimiento del honor como límite no supone una prevalencia de aquél, proclama que las libertades del artículo 20 no son sólo derechos fundamentales, sino que significan también el reconocimiento de la opinión pública, dimensión ésta de garantía que no se produce en el derecho al honor y que les otorga «una valoración que trasciende a la que es común y propia a todos los derechos fundamentales". Es decir, va a ser esa dimensión institucional a que nos referíamos anteriormente, la que sirva, a priori, a nuestra jurisprudencia constitucional, para atribuir a la libertad de expresión y al derecho a la información un carácter preferente.

Mayor significación, si se quiere, representa la sentencia 159/1986, de 16 de diciembre, relativa al caso Egin, en la cual tras señalar que los derechos fundamentales no son absolutos, como tampoco lo son los límites a los mismos, proclama que existe un régimen de concurrencia normativa y no de exclusión, gozando todos ellos de una fuerza expansiva que actúa sobre las normas limitadoras de los mismos, las cuales han de ser interpretadas restrictivamente. Junto a ello, la sentencia va a insistir en la dimensión institucional de los derechos reconocidos en el artículo 20, señalando que «en él se garantiza un interés constitucional, la formación y existencia de una opinión pública libre, garantia que reviste una especial trascendencia, ya que, al ser una condición previa y necesaria para el ejercicio de otros derechos inherentes al funcionamiento de un sistema democrático, se convierte, a su vez, en uno de los pilares de una sociedad libre y democrática». Por ello, existe una posición preferencial de estas libertades que implica, de una parte, «una mayor responsabilidad moral y juridica en quien realiza la información, de otra exige una rigurosa ponderación de cualquier norma o decisión que coarte su ejercicio». Y cuando se produce el conflicto con otros derechos fundamentales $u$ otros intereses,

- E. Gómez Reino y E. García Llovet: Legislación básica del derecho a la información, Tecnos, Madrid 1985, citan la sentencia 114/1984, de 29 de noviembre, recordando la expresión del Tribunal Supremo americano, utilizada en la sentencia U.S. vs. Carolene Products Co., 304, U.S. (1938), debida al juez Stone. Sobre la problemática general de las libertades preferentes en la jurisprudencia anglosajona y alemana, cfr. E. BARENDT: Freedom of Speech, Clarendon Press, Oxford 1987, citado por R. SORIANo: Las libertades públicas, Tecnos, Madrid 1990. 
su contenido fundamental, dada su jerarquía institucional, no puede ser relativizado ni desnaturalizado. $Y$ concluye la sentencia: «La libertad de información juega un papel esencial como garantía institucional del principio democrático que inspira nuestra Constitución, el cual presupone, como antes señalábamos, el derecho de los ciudadanos a contar con una amplia y adecuada información respecto de los hechos, que les permita formar sus convicciones y participar en la discusión relativa de los asuntos públicos».

Así pues, de esta doctrina jurisprudencial parecen deducirse dos consecuencias jurídicas: por un lado, esta posición preferencial, consecuencia directa del principio democrático, exige una responsabilidad moral y jurídica por parte del profesional de la información, $y$, por otro, hay que ponderar cualquier norma o decisión que coarte su ejercicio.

En la misma línea argumental insiste la sentencia 168/1986, de 22 de diciembre, en la cual, tras señalar que «el derecho a recibir una información veraz es, de este modo, un instrumento esencial de conocimiento de los asuntos que cobran importancia en la vida colectiva y que, por lo mismo, condiciona la participación de todos en el buen funcionamiento del sistema de relaciones democráticas auspiciado por la Constitución, así como el ejercicio efectivo de otros derechos y libertades", proclama que, en el supuesto de hecho contemplado, relativo a la revista Tiempo, no cabe una prevalencia del artículo 18.1, sino que se impone una ponderación y, en este juicio ponderado, prevalece, por tener una dimensión institucional, el derecho a la información.

Esta importante sentencia, sin embargo, no parece descender a todas las consecuencias que debe implicar el carácter preferente del derecho a la información. En efecto, tras proclamar su función en un sistema democrático, indicando que «el derecho a recibir una información veraz es, de este modo, un instrumento esencial de conocimiento de los asuntos que cobran importancia en la vida colectiva y que, por lo mismo, condiciona la participación de todos en el buen funcionamiento del sistema de relaciones democráticas auspiciado por la Constitución», concluye que, «por ello, resultan conculcados los derechos reconocidos en el artículo 20.1, d), de la Constitución, tanto si se impide comunicar o recibir una información veraz como si se difunde, se impone o se ampara, la transmisión de noticias que no responden a la verdad, siempre que ello suponga cercenar el derecho de la colectividad a recibir, sin restricciones o deformaciones, aquellas que sean veraces".

En parecidos términos va a pronunciarse la sentencia $165 / 1987$, de 27 de octubre, al reconocer que «la libertad de información es, en términos constitucionales, un medio de formación de la opinión pública en asuntos de interés general, cuyo valor de libertad preferente sobre otros derechos fundamentales... viene determinado por su condición de garantía de la opinión pública, que es una institución constitucional del Estado democrático». 
Y más adelante añade: «Este valor preferente alcanza su máximo nivel cuando la libertad es ejercitada por los profesionales de la información a través del vehículo institucionalizado de formación de la opinión pública, que es la Prensa, entendida en su más amplia acepción", prevalencia que desaparece cuando se ejercita, a través de cauces irregulares, como puede ser la emisión de hojas clandestinas, en cuyo caso ésta se invierte en favor del derecho al honor.

Pero sin duda alguna va ser la sentencia 107/1988, de 8 de junio, pronunciada con motivo del caso Diario 16, la que establezca de una forma más contundente el carácter preferente de estos derechos y libertades. A este respecto, el Tribunal, siguiendo la doctrina del Tribunal Europeo de Derechos Humanos, especialmente la establecida en su conocida sentencia del caso Ligens, de 8 de julio de $1986^{7}$, en la cual se va a proclamar que estas libertades poseen «un valor superior o eficacia irradiante».

En efecto, tras señalar que en el conflicto suscitado concluyen dos perspectivas «la que enjuicia o valora la conducta del sujeto en relación con el derecho al honor que se dice lesionado, y aquella otra cuyo objeto es valorar dicha conducta en relación con la libertad de expresión o información en ejercicio de la cual se ha invadido aquel derecho", establece que el órgano judicial debe realizar un juicio ponderativo «a fin de establecer si la conducta del agente se justifica por el valor predominante de la libertad de expresión en ejercicio de la cual se ha inferido la lesión".

$Y$ dicha valoración, es decir este juicio ponderativo, debe estar presidido por dos parámetros esenciales, «referido uno a la clase de libertad ejercitada - de expresión o de información- y, el otro, a la condición pública o privada de las personas afectadas por su ejercicio". En el primer caso, y partiendo de la distinción, a la cual luego aludiremós, entre el contenido de la libertad de expresión y del derecho a la intormación, establece el principio de que «mientras los hechos por su materialidad son susceptibles de prueba, los pensamientos, ideas y opiniones o juicios de valor, no se prestan, por su naturaleza abstracta, a una demostración de su exactitud y ello hace que al que ejercita la libertad de expresión no le sea exigible la prueba de la verdad o diligencia en su averiguación... y, por tanto,

7 Como recuerda entre nosotros F. Fernandez SEgado: «La libertad de expresión en la doctrina del Tribunal Europeo de Derechos Humanos», Revista de Estudios Politicos, núm. 70, el Informe de la Comisión Europea, formulado en el citado caso el 11 de octubre de 1984 resulta contundente: «El sistema democrático requiere que los que desempeñan una función en la vida pública se sometan a la estrecha fiscalización no sólo de sus adversarios políticos en las instituciones del Estado o en otras organizaciones, sino también de la opinión pública, la cual se forma y expresa en los medios de comunicación. El ejercicio de esta fiscalización no es meramente un derecho; puede considerarse incluso un deber y una responsabilidad de la Prensa en el Estado democrático» (nota 10, p. 97). 
la libertad de expresión es más amplia que la libertad de información por no operar en el ejercicio de aquélla el límite interno de veracidad que es aplicable a ésta". En el segundo caso, ese carácter preferente únicamente puede predicarse cuando se ejerciten en asuntos de interés público, tanto por razón de las materias como de las personas, contribuyendo así a la formación de la opinión pública, pues el derecho al honor tiene un significado personalista, no pudiendo referirse a las instituciones.

Hasta este momento parece que la línea jurisprudencial, con independencia de que convenzan o no sus planteamientos, y reconociendo que no deducen todas las posibles consecuencias jurídicas, mantiene una cierta coherencia y claridad. El carácter preferente de la libertad de expresión y del derecho a la información no tiene un carácter absoluto, sino que exige un juicio de ponderación en virtud del cual dichas libertades prevalecen siempre que se trate de asuntos o personas públicos, otorgándose un mayor ámbito a la libertad de expresión que al derecho a la información. No obstante, esta línea jurisprudencial va a empezar a quebrarse en sentencias posteriores.

En primer lugar, habría que mencionar la sentencia 121/1989, de 3 de julio, relativa al caso El Día, en la cual si bien la postura mayoritaria reitera la doctrina anterior, existe un importante voto particular, mantenido por el Sr. Díaz Eimil, que supone un replanteamiento de toda la jurisprudencia anterior. En efecto, partiendo de la idea de que la prevalencia no puede concebirse de un modo absoluto que haga ilusoria la condición del derecho al honor como derecho fundamental y como límite expreso a tenor de lo establecido en el artículo 20.4 , señala que no puede concederse «a ese valor prevalente una excesiva eficacia que vaya más allá del tratamiento que ambos derechos fundamentales merecen». Por ello, establece la necesidad de abandonar el criterio de la prevalencia formal, propugnando el uso de los criterios materiales que han de «tener presente cuáles son las ideas dominantes que la sociedad tiene sobre el valor de cada uno de dichos derechos", función para la cual están más capacitados los jueces ordinarios que el Tribunal Constitucional, el cual no puede convertirse en una instancia de jurisdicción penal, debiendo ceder ante el juicio de prevalencia realizado por los Tribunales ordinarios.

En esta nueva línea jurisprudencial, y sin que ello suponga reconocer un hilo conductor en relación con los planteamientos del voto particular anterior, habría que mencionar tres sentencias polémicas que han sido objeto de una fuerte controversia, tanto a nivel doctrinal, como a través de los propios medios de comunicación, poniéndose de relieve, en alguno de ellos, ideas tales como el carácter involucionista de nuestra jurisprudencia constitucional, que ha abandonado el principio de la seguridad juridica y se ha situado en épocas preconstitucionales ${ }^{8}$.

\& Cfr., a modo de ejemplo, los artículos de prensa de E. GIMBERnAT: «EI 
En primer lugar, nos encontramos con la sentencia 105/1990, de 6 de junio, relativa al caso José María Garcia, en la cual tras señalar los criterios en que debe sustentarse la decisión del Tribunal (ponderación entre los derechos en presencia, requisitos que debe presidir tal ponderación y la veracidad en la información), proclama, siguiendo la jurisprudencia anterior, que no son derechos absolutos y que tampoco tienen este carácter las limitaciones a que han de someterse. A continuación, tras reiterar que la libertad de expresión se refiere a juicios y a opiniones, y el derecho a la información a la manifestación de los hechos, señala que la primera sólo encuentra su límite en la utilización de expresiones injuriosas, y la segunda sólo protege la información veraz, acudiendo a la diferenciación entre personas públicas y privadas. Finalmente, al analizar la veracidad en la información, tras reiterar que la información errónea no está exenta de protección, y tras reconocer que el recurrente en amparo habia transmitido hechos veraces, concluye que la emisión de apelativos injuriosos son innecesarios para el ejercicio de la labor informativa y que la Constitución no reconoce el derecho al insulto, razón por la cual deniega el amparo solicitado. Es decir, parece volverse a la tesis del animus iniuriandi, caracteristico de nuestra jurisdicción ordinaria preconstitucional y que parecía haber sido abandonado.

En segundo lugar, habria que referirse a dos sentencias, las números $171 / 1990$ y 172/1990, ambas de 12 de noviembre, en las cuales se enjuician unos mismos hechos, relativos a un accidente de aviación de relevancia pública, cuya información había aparecido en los diarios El País y Diario 16, llegando a consecuencias juridicas diferentes.

En la primera de ellas, tras reconocer la vigencia de determinados preceptos de la Ley de Prensa e Imprenta de 1966, como son los artículos $37,40.1$ y 62.1 , reproduce la doctrina de sentencias anteriores, relativa al carácter preferente de la libertad de expresión, a la ponderación de los derechos en presencia, a la relevancia pública de la información, etc., proclamando que existe una relevancia pública y social del supuesto de hecho contemplado y que la regla de la veracidad no exige que los hechos sean rigurosamente ciertos, razón por la cual el derecho fundamental del artículo 20 no puede restringirse a la comunicación objetiva y aséptica de los hechos. Es decir, reproduce la doctrina anterior de la prevalencia del artículo 20 sobre el artículo 18.1. Sin embargo, la sentencia 172/1990, ante el mismo supuesto de hecho, llega a consecuencias jurídicas distintas. En efecto, tras admitir que cada información periodística constituye un acto individual, debiendo, por tanto, resolverse los recursos interpuestos con total independencia, proclama que si bien estamos en presencia de liber-

Tribunal Constitucional cambia de opinión", diario El Mundo, 27 de noviembre de 1990, y de T. GonzAlez BALlesteros: "Una sentencia del Tribunal Constitucional», Tribuna, 10 de diciembre de 1990. 
tades preferentes, esta preferencia no tiene un carácter absoluto, denegando el correspondiente amparo.

b) Relaciones entre la libertad de expresión y el derecho a la información

La constitucionalización de dos derechos fundamentales en los apartados a) y d) del artículo 20 ha planteado no pocos problemas, tanto a nuestra doctrina como a nuestra jurisprudencia. Pensemos en aquellas posturas doctrinales que consideraban innecesaria la constitucionalización del derecho a la información por entenderlo incluido en la libertad de expresión, o en aquellas otras que distinguian entre derechos sustanciales y derechos instrumentales, sin olvidar las que hablaban de la existencia de auténticos derechos naturales ${ }^{9}$. También nuestra jurisprudencia constitucional ha experimentado una línea evolutiva, aún no definitivamente consolidada y de la cual no parecen haberse deducido todas las consecuencias jurídicas posibles, tardando bastante tiempo en diferenciar el contenido y significado de uno y otro derecho.

En primer lugar, habria que mencionar la ya citada sentencia 6/1981, de 16 de marzo, en la cual, tras proclamar el carácter de derecho de libertad del apartado a), señala que «otro tanto cabe afirmar respecto del derecho a comunicar y recibir información veraz, fórmula que, como es obvio, incluye dos derechos distintos, pero íntimamente conectados. El derecho a comunicar que, en cierto sentido, puede considerarse como una simple aplicación concreta de la libertad de expresión y cuya explicitación diferenciada sólo se encuentra en textos constitucionales recientes, es derecho del que gozan también, sin duda, todos los ciudadanos, aunque en la práctica sirva sobre todo de salvaguardia a quienes hacen de la búsqueda y difusión de la información su profesión específica; el derecho a recibir es, en rigor, una redundancia (no hay comunicación cuando el mensaje no tiene receptor posible), cuya inclusión en el texto constitucional se justifica, sin embargo, por el propósito de ampliar al máximo el conjunto de los legitimados para impugnar cualquier perturbación de la libre comunicación social». Así pues, en esta primera sentencia, nuestro Tribunal aún no parece ser plenamente consciente de la distinta significación de los derechos constitucionalizados en los apartados a) y d).

Una mayor concreción se va a producir en la también citada sentencia 105/1983, de 23 de noviembre, relativa al caso Vinader, en la cual

9 Cfr. la bibliografía citada en nota 4 . 
tras señalar que estamos en presencia de dos derechos fundamentales distintos, constitucionalizados «en aras del interés colectivo en el conocimiento de hechos que puedan encerrar transcedencia pública y que sean necesarios para que sea real la participación de los ciudadanos en la vida colectiva", concluye que estamos en presencia de "un derecho doble que se concreta en comunicar la información y recibirla de manera libre en la medida en que la información sea veraz. El objeto de este derecho es, por consiguiente, el conjunto de hechos que puedan considerarse como noticiables o noticiosos en los términos puntualizados anteriormente y de él es sujeto primero la colectividad y cada uno de sus miembros, cuyo interés es el soporte final de este derecho, del que es asimismo sujeto, órgano o instrumento, el profesional del periodismo, puesto que a él concierne la búsqueda de la información y su posterior transmisión».

Esta línea de delimitación jurisprudencial va a verse sumamente enriquecida con la iniciada a partir de la sentencia 6/1988, de 21 de enero, relativa al caso Crespo Martínez, en la cual parece efectuarse una adecuada delimitación de la libertad de expresión y del derecho a la información. La sentencia empieza afirmando que ambos derechos tienen un contenido diferente y también lo son sus límites y efectos: "La libertad de expresión tiene por objeto pensamientos, ideas y opiniones, concepto amplio dentro del que deben incluirse también las creencias y juicios de valor. El derecho a comunicar y recibir libremente información versa, en cambio, sobre hechos, o tal vez más restringidamente, sobre aquellos hechos que pueden considerarse noticiables". Ahora bien, como esta diferenciación puede no producirse de una forma nítida en la realidad, pues la expresión de pensamientos necesita apoyarse en hechos y la comunicación de éstos no se produce nunca en estado químicamente puro, comprendiendo siempre algún elemento valorativo, habrá que acudir al elemento preponderante en cada caso.

Asimismo, la sentencia analiza la necesidad de que la información sea veraz, señalando que, con ello, «no se está privando de protección a las informaciones que puedan resultar erróneas... cuanto estableciendo un específico deber de diligencia sobre el informador». Es decir, el ordenamiento jurídico no ofrece su protección a conductas negligentes, sino a la «información rectamente obtenida y difundida", concluyendo que "aunque no deja de amparar las informaciones controvertibles, se requiere de quien las transmite una especifica diligencia, ya que el Derecho constitucional no ampara no ya la información que se sabe inexacta por quien la transmite, sino la que, difundida sin contraste alguno con datos objetivos y carentes de toda apoyatura física, se revela después como no acreditada en el curso de un proceso". Como apuntábamos en líneas anteriores, esta diferenciación entre los contenidos de la libertad de expresión y del derecho 
a la información dará lugar a un tratamiento jurídico distinto de su carácter de libertades preferentes ${ }^{10}$.

\section{c) Su contenido}

No se trata aqui de analizar el contenido de las libertades de expresión y del derecho a la información, cuestión sobre la cual volveremos, de un modo más específico, al abordar la problemática de la Prensa, sino únicamente de plantear una cuestión que ya habia sido apuntada cuando estudiábamos su condición de auténticos derechos de libertad. Es decir, partiendo de su configuración jurisprudencial como auténticos derechos de libertad, lo que no debe impedirnos olvidar su dimensión institucional que, a la postre, servirá de criterio determinante, para configurarlos como libertades preferentes, se trata de analizar si estos derechos y libertades engloban también el derecho a crear y disponer de los medios materiales para su ejercicio. La cuestión que, en nuestra jurisprudencia constitucional, se planteó en primer lugar en relación con la Prensa y, posteriormente, en relación con la televisión, en el fondo lo que se suscita es la propia naturaleza de las empresas informativas, cuestión que abordaremos más adelante, y que pone sobre el tapete las relaciones entre los derechos constitucionalizados en el artículo 20 y la libertad de empresa del artículo 38, sistema de relaciones que según sea la solución adoptada conllevará consecuencias jurídicas muy distintas.

Sobre el tema en cuestión, desde un punto de vista doctrinal, se han mantenido las dos tesis. Mediante la primera se señala que el derecho a crear los medios materiales para la difusión encuentra su fundamento constitucional en el artículo 38 y no en el artículo 20, poniéndose como ejemplo lo establecido en el artículo 27.6, sobre el derecho a crear centros docentes, pues si el constituyente lo hubiese querido mencionar expresamente lo hubiera hecho. La segunda de las tesis mantiene la postura contraria, en el sentido de que el derecho a crear los medios de difusión encuentra su fundamento constitucional en el propio artículo 20, formando parte del contenido esencial de las libertades de expresión y del derecho a la información, concebidos éstos como auténticos derechos complejos ${ }^{11}$.

10 Esta acertada línea jurisprudencial va a verse continuada en posteriores decisiones, como revelan, entre otras, las sentencias 107/1988, de 8 de junio, y 51/ 1989, de 22 de febrero.

11 Cfr. ambas posturas en F. LÓPEz RAMÓN: «La evolución del régimen jurídico de la libertad de Prensa tras la Constitución de 1978», REDA, núm. 34, pp. 383 y ss., y F. J. BASTIDA: La libertad de antena. El derecho a crear televisión, Ariel, Barcelona 1990. Cfr., asimismo, C. ChINCHILLA MARIN: «Derecho de información, libertad de expresión y opinión pública libre», Poder Judicial, núm. 3, 1986, y C. Molinero Santamaria: "Las empresas y los medios de comunicación social», en La empresa en la Constitución española, Ed. Aranzadi, Pamplona 1988. 
La cuestión ya se planteó en la reiterada sentencia 6/1981, de 16 de marzo, al analizarse el significado del artículo 20.3 de la Constitución, señalándose que «esta norma no fija, sin embargo, en modo alguno, cuál haya de ser la naturaleza, el número o la ubicación geográfica de los medios de comunicación social dependientes del Estado o de otros entes públicos, ni reserva a la Ley su creación o supresión... La libertad de los medios de comunicación, sin la cual no sería posible el ejercicio eficaz de los derechos fundamentales que el artículo 20 de la Constitución enuncia, entraña seguramente la necesidad de que los poderes públicos, además de no estorbarla, adopten las medidas que estimen necesarias para remover los obstáculos que el libre juego de las fuerzas sociales podrían oponerle".

Y ello, continúa la sentencia, porque «el mandato del 20.3... concede a estos grupos el derecho a exigir que no se haga nada por impedir dicho acceso, pero aunque la libertad de los medios de comunicación entraña seguramente la necesidad de que los poderes públicos, además de no estorbarla, adopten las medidas que estimen necesarias para remover los obstáculos que se le opongan, no cabe derivar, sin embargo, de tal obligación el derecho a exigir el sostenimiento de un determinado medio de comunicación de carácter público».

Este criterio del Tribunal Constitucional, referido fundamentalmente a la prensa, va a verse modificado en la sentencia 12/1982, de 31 de marzo, para el supuesto de la televisión. En efecto, tras reiterar la doctrina mantenida en la sentencia citada anteriormente, en el sentido de que "no hay inconveniente en entender que el derecho de difundir las ideas y opiniones comprende, en principio, el derecho de crear los medios materiales a través de los cuales la difusión se hace posible», sin embargo, señala que este derecho a crear los soportes o instrumentos de comunicación no es un derecho absoluto, sino que también tiene sus límites, entre los cuales hay que tener en cuenta el carácter de los propios bienes y los problemas técnicos que pueda plantear.

Desde este planteamiento, la sentencia niega la existencia de un derecho a la televisión privada, remitiendo la cuestión al legislador y concluyendo que «la preservación de la comunicación pública libre, sin la cual no hay sociedad libre ni soberania popular, no exige sólo la garantía del derecho de todos los ciudadanos a la expresión del pensamiento y a la información, sino que requiere también la preservación de un determinado modo de producirse de los medios de comunicación social, porque tanto se viola la comunicación libre al ponerse obstáculos desde el poder, como al ponerle obstáculos desde los propios medios de difusión».

Como es sabido, esta tesis mayoritaria del Tribunal, consistente en negar el derecho a la televisión privada, aunque su existencia no esté tampoco prohibida por la Constitución, es refutada por un importante voto particular del Sr. Rubio Llorente, en el cual tras reconocer que la Constitución "consagra también el derecho a crear los medios de comunicación indispensables para el ejercicio de estas libertades", y tras señalar que si bien 
no son derechos de prestación, pero tampoco simples derechos reacionales, concluye que éstos no pueden ser ejercidos en ausencia de organización, debiendo, por tanto, dictarse por el legislador las normas organizativas correspondientes para el ejercicio de los derechos fundamentales; es decir, se muestra contrario al monopolio estatal de la televisión, concluyendo que la Constitución reconoce un derecho a la televisión privada y que el legislador viene obligado a dictar las correspondientes normas organizativas para el ejercicio de este derecho.

En un asunto también relativo a la problemática de la televisión privada, la sentencia 74/1982, de 20 de diciembre, vuelve a insistir sobre la misma idea: «No hay inconveniente en defender la necesidad de crear los medios materiales, a través de los cuales la difusión de pensamientos, ideas y opiniones se hace posible, pero no se puede omitir que este derecho presenta indudables límites por la necesidad de no impedir un igual ejercicio de los mismos derechos por los demás ciudadanos, sobre todo cuando nos enfrentamos a un medio de reproducción caracterizado por su grado de escasez natural, cual es la televisión».

$Y$ es que en nuestra doctrina jurisprudencial parece que hay que distinguir, como expresamente se establece en el Auto 237/1985, de 10 de abril, dentro del artículo 20 , «lo que realmente constituye el contenido de la libertad de expresión y del derecho a comunicar y recibir información, por un lado, de los posibles derechos o facultades relativos a los medios o soportes materiales necesarios para difundir el pensamiento o para comunicar o recibir información, por otro».

Es decir, por un lado, nuestra jurisprudencia parece contundente al proclamar que el derecho a crear los medios de expresión forma parte del contenido esencial de la libertad de expresión y del derecho a la información. Por lo tanto, este derecho encuentra su fundamento constitucional en el propio artículo 20 y no, como pudiera deducirse de alguna de las posturas doctrinales antes mencionadas, en el derecho a la libre empresa constitucionalizado en el artículo 38. Las consecuencias juridicas de una $u$ otra concepción son evidentes y no necesitan ser resaltadas.

Ahora bien, este derecho a crear los medios materiales está en función del propio medio de reproducción de la noticia, siendo más amplio para unos casos, como sucede en el supuesto de la Prensa, que para otros, donde encuentra unos límites más restringidos por la naturaleza del propio medio. Es el caso de la radiotelevisión ${ }^{12}$.

12 Sobre esta problemática, y especialmente por lo que a la televisión se refiere, cfr., entre otros, las diferentes posiciones mantenidas por S. VARELA: "Constitución, monopolio y televisión», Revista de Derecho Politico, núm. 6, pp. 37 y ss.; T. Quadra SALCEdo: «La televisión privada y la Constitución», Revista de Derecho Público, núm. 14, pp. 57 y ss.; F. GonzAlez NAvarro: Televisión pública y televisión 


\section{LA PRENSA EN EL CONSTITUCIONALISMO HISTÓRICO ESPAÑOL Y EN EL DERECHO COMPARADO}

Las páginas siguientes pretenden únicamente ofrecer un marco referencial sobre la regulación de la Prensa en nuestro constitucionalismo histórico y en el ámbito del Derecho Comparado que sirva como antecedente para el posterior estudio del régimen jurídico de la Prensa en nuestro pais.

\section{a) El constitucionalismo histórico español}

Como es sabido, la libertad de Prensa fue una de las grandes conquistas del movimiento liberal frente a los postulados del Antiguo Régimen, pudiendo afirmarse que, pese a su singularidad, nuestro constitucionalismo histórico difícilmente podría ser entendido si no es mediante el análisis del florecimiento de la Prensa periódica en nuestro pais ${ }^{13}$.

Ciertamente, la aparición de la Prensa es anterior al establecimiento del régimen liberal, aunque únicamente dentro de él adquiere su pleno significado. Asi, podemos afirmar que durante la Edad Media, la libertad de pensamiento no podia trascender de la libertad de conciencia ni ésta lograr su expresión. Pensemos en el significado de la aparición de la imprenta y cómo ya en 1480 se puede hablar, aunque no en sentido técnico, de la "primera ley de imprenta", hecha pública en Toledo.

privada, Civitas, Madrid 1982; F. SAINz MORENO: «La regulación legal de la televisión privada en la jurisprudencia constitucional», Revista Española de Derecho Constitucional, núm. 2, pp. 159 y ss.; C. CHINCHILLA: La radiotelevisión como servicio público esencial, Tecnos, Madrid 1988; etc. El debate doctrinal se ha pacificado, en buena medida, tras materializarse la opción por la televisión privada en la Ley Orgánica $2 / 1988$, de 3 de mayo, cuyo contenido, sin duda polémico, se escapa a las pretensiones del presente estudio.

${ }_{13}$ Sobre la historia de la Prensa en nuestro país, cfr., con carácter general, E. Gómez Reino: Aproximación histórica al derecho de la imprenta y de la Prensa en España (1480-1966), IEA, Madrid 1977, y «Nuevas perspectivas para la reforma de la Prensa en España», RAP, núm. 84, 1977, pp. 322 y ss.; EguizÁBAL: Apuntes para una Historia de la legislación española de la imprenta, Imprenta de la Revista de Legislación, Madrid 1877; F. CendAN PAZos: Historia del derecho español de Prensa e imprenta (1502-1966), Editora Nacional, Madrid 1974; J. BENEYTO: «Los orígenes del derecho a ser informado", Revista Persona y Derecho, vol. V, Pamplona 1978; C. Molinero: Teoría y fuentes del derecho a la información, PPU, Barcelona 1989. 
El régimen de la imprenta durante la Monarquía absoluta va a caracterizarse por una serie de notas ${ }^{14}$, entre las cuales hay que mencionar la necesidad de un sistema de licencia real para poder imprimir, la aplicación de las normas punitivas a los que se apartaban del proteccionismo oficial que, a veces, se manifestaba a través del sistema de licencias individuales, y la creación por parte del poder político de aparatos propios de difusión de noticias, es decir, la creación de una opinión oficial. Baste recordar, a este respecto, la Pragmática dictada por los Reyes Católicos el 8 de julio de 1502; la Pragmática Sanción de 7 de septiembre de 1558, dictada por Felipe II, que puede ser considerada como el primer reglamento administrativo para la imprenta; el Real Decreto de 15 diciembre de 1749, firmado por Fernando Vl; las diferentes Reales Órdenes dictadas bajo el reinado de Carlos III, y, finalmente, el Decreto de 11 de abril de 1805, de Carlos IV.

Sin duda alguna, la Revolución inglesa va a suponer, como en tantas otras cuestiones, un auténtico hito en la historia de la libertad de imprenta. La publicación, en 1644, del Aeropagita de MILTON, constituye una fecha de obligada referencia histórica. Pero va a ser a lo largo del siglo XVIII donde la libertad de Prensa se vaya configurando como una auténtica manifestación de la libertad de expresión, pese a que no será hasta el siglo XIX cuando los diarios adquieran un auténtico carácter informativo y de opinión.

En nuestra historia constitucional, la libertad de imprenta va seguir la evolución y presentar las características propias de nuestros textos constitucionales ${ }^{15}$.

La Constitución de Bayona, de 7 de julio de 1808, en su artículo 145 preveia el establecimiento de la libertad de imprenta, dos años después de haberse ejecutado enteramente la Constitución, a través de una ley que nunca llegó a aprobarse. Análogas consideraciones podrian hacerse sobre el artículo 39, que atribuía al Senado la facultad de velar por la libertad individual y la libertad de imprenta, preveyéndose, en el artículo 45, una junta de cinco senadores para ejercer esta función.

Durante el régimen de las Cortes de Cádiz habría que mencionar, en primer lugar, el Decreto de 14 de noviembre de 1810, más tarde convertido en Ley por las propias Cortes el dia 19 de marzo de 1812, que instituye un régimen liberal de la libertad de Prensa, que más tarde sería

14. Cfr., a este respecto, M. VÁZQuez MONTALBÁN: Historia de la comunicación social, Barcelona 1980, pp. 95 y ss.

15 Cfr. M. C. Seonne: Historia del periodismo en España, Madrid 1983, y P. Gómez Aparicio: Historia del periodismo español, Madrid 1967. 
constitucionalizado en el artículo 371 del texto gaditano ${ }^{16}$. Este régimen liberal seria suprimido por el Decreto de 4 de mayo de 1814, volviendo a renacer con la Ley de 22 de octubre de 1820, que acentúa el régimen de intervención administrativa en la libertad de prensa, junto al establecimiento del jurado.

Durante el reinado de Isabel II hay que mencionar, en primer lugar, èl Reglamento de Prensa de 4 de enero de 1834. Posteriormente, los diferentes textos constitucionales ${ }^{17}$ reconocerian, con mayor o menor restricción, el principio de la libertad de imprenta sin censura previa, aceptándose o suprimiéndose el sistema de jurados. En cuanto a la normativa de desarrollo, hay que citar la Ley de Prensa de 22 de marzo de 1837, donde se efectúa una definición legal del periódico, se restablece el juicio por jurados y se reconoce el derecho de respuesta. Esta Ley sería derogada por la llamada Ley Nocedal, de 13 de julio de 1857, que supuso un endurecimiento del régimen de Prensa, imponiendo un sistema de elevados depósitos pecuniarios, a su vez reformada por las Leyes de 22 de junio de 1864 y, principalmente, por la Ley González Bravo, de 7 de marzo de 1867, sin duda la más restrictiva de todas ellas.

La Constitución de 1869 representa un salto cualitativo en el régimen de la libertad de Prensa, reconociéndose en su artículo 17 el derecho a la libre emisión de ideas y opiniones "ya de palabra, ya por escrito, valiéndose de la imprenta o de otro procedimiento semejante".

Durante la Restauración, el artículo 13 de la Constitución de 1876 reproduce las líneas esenciales de la Constitución de 1869 , mencionando expresamente la prohibición de censura previa. En cuanto a la normativa de desarrollo, hay que mencionar dos leyes, la Ley de 7 de enero de 1879 $y$, fundamentalmente, la Ley de 26 de julio de 1883, que es la ley liberal por antonomasia de nuestro régimen constitucional ${ }^{18}$.

16 El artículo 371 de la Constitución de 1812 disponía: «Todos los españoles tienen libertad de escribir, imprimir y publicar sus ideas políticas, sin necesidad de licencias, revisión o aprobación alguna anterior a la publicación, bajo las restricciones y responsabilidad que establecen las leyes".

${ }_{17}$ El artículo 2 de la Constitución de 1837 disponia: "Todos los españoles pueden imprimir y publicar libremente sus ideas sin previa censura, con sujeción a las leyes. La calificación de los delitos de imprenta corresponde exclusivamente a los jurados". Por su parte, el artículo 2 de la Constitución de 1845 suprime el último inciso relativo a los jurados y, finalmente, el articulo 3 de la Constitución non nata de 1856 añade el siguiente apartado: «No se podrá secuestrar ningún impreso hasta después de haber empezado a circular. La calificación de los delitos de imprenta corresponde a los jurados".

18 Sobre el significado de esta ley, cfr. C. SoriA: «La ley española de Policía de Imprenta de 1883", Documentación de las Ciencias de la Información, vol. VI, Universidad Complutense, Madrid 1982. 
Durante la II·República, el derecho a la libre emisión de ideas y opiniones va a constitucionalizarse en el artículo 34 , prohibiéndose la censura previa y la suspensión de los periódicos a no ser por sentencia firme. No obstante, determinadas disposiciones supusieron una cierta modalidad de censura previa, tales como el Decreto de 29 de mayo de 1934 y la propia Ley de Defensa de la República, de 21 de octubre de $1931^{19}$.

Finalizada la guerra civil se dictó la Ley de Prensa de 22 de abril de 1938, que era una auténtica ley de Policia, propia de la época en la que se dictó y de los postulados ideológicos del nuevo régimen. Posteriormente, se aprobaria la Ley de Prensa e Imprenta de 18 de marzo de 1966, la llamada Ley Fraga, que supuso un paso importante en la evolución dentro del régimen franquista, y sobre cuya vigencia actual volveremos en páginas siguientes.

b) La Prensa en el Derecho Comparado

La regulación de la Prensa en el Derecho Comparado presenta una gran heterogeneidad ${ }^{20}$, como consecuencia del distinto significado de las Constituciones que se aprueban tras la Segunda Guerra Mundial. No es nuestro propósito proceder al análisis minucioso del régimen jurídico de la Prensa en los diferentes países, sino tan sólo ofrecer un marco referencial adecuado para nuestro estudio.

En Francia, el ordenamiento básico está constituido por el artículo 11 de la Declaración de Derechos del Hombre y del Ciudadano, de 23 de agosto de 1789, y por la Ley de 29 de julio de 1881, posteriormente modi-

19 El artículo 34 de la Constitución de 1931 disponía: «Toda persona tiene derecho a emitir libremente sus ideas y opiniones, valiéndose de cualquier medio de difusión, sin sujetarse a la censura previa. En ningún caso podrá recogerse la edición de libros y periódicos sino en virtud de mandamiento de juez competente. No podrá decretarse la suspensión de ningún periódico sino por sentencia firme». Por su parte, el artículo 1 de la Ley de Defensa de la República consideraba como actos de agresión a la misma, «la difusión de noticias que puedan quebrantar el crédito o perturbar la paz o el orden público». Sobre su significado, cfr. R. ABAD Amorós: "Estudio en torno a la Ley de Defensa de la República», Revista de Ciencias de la Información, núm. 3, Madrid 1986.

${ }^{20}$ Cfr. una breve panorámica del Derecho Comparado en J. M. Souvirón: Notas para una ley sobre la información, Instituto Nacional de Prospectiva, Madrid 1980. 
ficada y complementada por normas específicas en determinadas materias ${ }^{21}$.

En Italia, la libertad de Prensa está garantizada por el artículo 21 de la Constitución de 1947, uno de los preceptos tenidos en cuenta por nuestros constituyentes, y por la Ley de Prensa de 8 de febrero de 1948, posteriormente modificada por numerosas normas específicas ${ }^{22}$.

La Constitución portuguesa de 1976 es, junto con la española, la que más novedades introduce en el régimen de la libertad de expresión y del derecho a la información, tal y como revelan los artículos 37 y 38 , posteriormente desarrollados por la Ley de Prensa de 25 de febrero de 1975 y otras disposiciones posteriores ${ }^{23}$.

En Alemania, la libertad de Prensa aprece constitucionalizada en el artículo 5 de la Ley Fundamental de Bonn, no existiendo una única ley reguladora de la Prensa y de la información, sino una pluralidad de leyes emanadas de los diferentes länders ${ }^{24}$.

En Inglaterra, como era de esperar, el derecho a la libertad de Prensa no está garantizdo por ninguna norma en concreto, salvo en algunas materias puntuales ${ }^{25}$.

En Bélgica, el régimen viene establecido por la Constitución de 1831 y desarrollado normativamente por el Decreto de 20 de julio de 1831, sobre la Prensa, así como por una pluralidad de normas posteriores ${ }^{26}$.

21 Entre ellas, podrían mencionarse las siguientes: Ley de 2 de julio de 1931; Ley de 25 de marzo de 1952; Ley de 24 de julio de 1966, sobre las sociedades comerciales; Ley de Presupuestos de 1981 y 1983; Ley de 16 de mayo de 1984; Ley de 23 de octubre de 1984, tendente a limitar la concentración de empresas informativas; Ley de 1 de agosto de 1986, sobre la reforma del régimen jurídico de la prensa.

${ }^{22}$ Cfr. la Ley de 3 de febrero de 1963, reguladora de la profesión periodística; Ley de 17 de julio de 1975; Ley 6 de junio de 1978; Ley de 5 de agosto de 1981; Ley de 23 de diciembre de 1982; Ley de 25 de febrero de 1987; Ley de 22 de diciembre de 1989 y la llamada Ley MAMmI de 1990. Cfr., entre nosotros F. J. BASTIDA: La libertad de antena, cit., donde se analiza, doctrinal y jurisprudencialmente, el modelo italiano de libertad de Prensa.

${ }^{23}$ El modelo portugués, como había hecho también el británico y el alemán, instituye el régimen de los Consejos de Prensa a fin de garantizar la libertad de ésta tanto frente al poder político como frente a los poderes económicos. Cfr., entre nosotros, M. CARRILLO: «Los Consejos de Prensa como forma de autocontrol", REP, núm. 34 .

24 Cfr. la Ley de 27 de julio de 1957, de limitación contra la concurrencia.

25 Cfr., a modo de ejemplo, el Broadcasting Act de 1990.

${ }^{26}$ Cfr., entre otras, la Ley de 23 de junio de 1961, sobre el derecho de rectificación; la Ley de 18 de julio de 1985, relativa a la publicación de encuestas, asi como numerosos Decretos reales, que regulan diversos aspectos del régimen jurídico de la Prensa. 
Finalmente, podríamos mencionar otros países como los Estados Unidos y su Newspaper Preservation Act, o como Suecia, donde la regulación del tema ha adquirido una dimensión constitucional con la aprobación de lạ Ley Fundamental de Prensa de 1975.

\section{c) La regulación internacional de la libertad de Prensa}

El régimen jurídico de la Prensa en nuestro país no puede limitarse al estudio de los preceptos constitucionales y normas de desarrollo de los mismos, sino que en virtud de lo establecido en el artículo 10.2 de la Constitución, también forman parte de nuestro ordenamiento jurídico los Tratados y Convenios Internacionales debidamente ratificados por España. Asimismo, también hay que tener en cuenta las disposiciones emanadas de la Comunidad Económica Europea en materia de Prensa ${ }^{27}$.

A este respecto, en primer lugar habría que citar la Declaración Universal de Derechos Humanos, aprobada por la ONU el 10 de diciembre de 1948 , la cual si bien es dudoso que tenga una eficacia jurídica directa, dispone en su artículo 19:

«1. Todo individuo tiene derecho a la libertad de opinión y de expresión; este derecho incluye el de no ser molestado a causa de sus opiniones, el de investigar y recibir informaciones y opiniones, y el de difundirlas, sin limitación de fronteras, por cualquier medio de expresión.

2. Toda persona tiene derecho a la libertad de expresión. Este derecho comprende la libertad de buscar, recibir, difundir informaciones e ideas de toda índole, sin consideración de fronteras, ya sea oralmente, por escrito o en forma impresa o artística, o por cualquier otro procedimiento de su elección”.

Mayor importancia parece tener el Pacto Internacional de Derechos Civiles y Políticos, cuyo artículo 19.1 establece que «nadie podrá ser molestado a causa de sus opiniones", y, de forma especial, el Convenio para la Protección de los Derechos Humanos y de las Libertades Fundamentales

${ }^{27}$ Cfr., a este respecto, los trabajos de A. SÁnCHEZ Bravo: Europa y la Información (Prensa), Fundación Universidad Empresa, Madrid 1989; R. M. García SANZ: El derecho a opinar libremente, Eudema, Madrid 1990, así como los diferentes trabajos publicados en el libro colectivo Informe sobre la Información: España 1990, Banco Bilbao Vizcaya, 1990. 
de Roma, de 4 de noviembre de 1950, cuyo artículo 10, que ha servido de texto básico para la elaboración de la jurisprudencia del Tribunal Europeo de Derechos Humanos ${ }^{28}$, dispone:

«1. Toda persona tiene derecho a la libertad de expresión. Este derecho comprende la libertad de opinión y la libertad de recibir o de comunicar informaciones o ideas sin que pueda haber injerencia de autoridades públicas y sin consideración de fronteras. El presente artículo no impide que los Estados sometan las empresas de radiodifusión, de cinematografía o de televisión a un régimen de autorización previa.

2. El ejercicio de estas libertades, que entrañan deberes y responsabilidades, podrá ser sometido a ciertas formalidades, condiciones, restricciones o sanciones previstas por la Ley, que constituyan medidas necesarias, en una sociedad democrática, para la seguridad nacional, la integridad territorial o la seguridad pública, la defensa del orden y la prevención del delito, la protección de la salud o de la moral, la protección de la reputación o de los derechos ajenos, para impedir la divulgación de informaciones confidenciales o para garantizar la autoridad y la imparcialidad del poder judicial".

Junto a estos Tratados y Convenios Internacionales existen otras, de menor trascendencia política, que se refieren también a la problemática de la libertad de expresión ${ }^{28}$ bis.

${ }^{28}$ El Tribunal Europeo de Derechos Humanos se ha pronunciado ya en diversas ocasiones sobre el significado de este artículo 10, influyendo notoriamente en la jurisprudencia de los Tribunales Constitucionales de los Estados miembros. Entre las decisiones más significativas, cfr. las de 7 de diciembre de 1976 (caso Handyside), de 26 de abril de 1979 (caso The Sunday Times), de 25 de marzo de 1985 (caso Barthold), de 2 de julio de 1986 (caso Lingens, sin duda el más conocido de todos), de 28 de agosto de 1986 (caso Glasenapp), de 28 de agosto de 1986 (caso Koniek), de 24 de mayo de 1988 (caso Muller).

${ }_{28}$ bis Entre ellos habría que mencionar el artículo 5, apdo. d), párrafo 8 de la Convención Internacional sobre eliminación de todas las formas de discriminación racial; el artículo 1 de la Convención referente a la Institución del Derecho Internacional de Rectificación, así como todos aquellos Tratados y Convenios Internacionales que a la hora de regular el principio de igualdad y enumerar las causas o motivos de discriminación incluyen la libertad de opinión de forma expresa (art. 2.2 del Pacto Internacional de Derechos Económicos y Sociales; arts. 2 y 26 del Pacto Internacional de Derechos Civiles y Politicos; el art. 1.1 de la Convención relativa a la lucha contra las discriminaciones en materia de enseñanza; el art. 1.1, a), del Convenio relativo a la discriminación en materia de empleo y ocupación; el art. 1 del Convenio relativo a la abolición del trabajo forzoso, y un largo etcétera). 
En cuanto a la normativa emanada de la Comunidad Europea, habria que citar la Directiva de 3 de octubre de 1989, sobre radiodifusión televisiva, cuyo análisis se escapa al ámbito del presente estudio.

\section{EL RÉGIMEN JURÍDICO DE LA PRENSA EN ESPAÑA}

\section{a) Introducción}

El determinar el régimen jurídico de la Prensa en nuestro pais no es una tarea sencilla, debido al problema existente en torno a la vigencia o no de determinados aspectos parciales de la Ley de Prensa e Imprenta de 18 de mayo de 1966. No obstante, con ser éste el problema fundamental a analizar, se plantean otras cuestiones, unas de indole teórica y otras como consecuencia de la variada normativa de desarrollo existente.

Anteriormente hemos puesto de manifiesto que el precepto constitucional a tener en cuenta es el artículo 20 , donde se reconocen, dentro de su heterogeneidad, la libertad de expresión y el derecho a la información. Junto a ello, hay que destacar también la existencia de otros preceptos constitucionales, como el artículo 46, que reconoce el derecho a la documentación ${ }^{29}$; el artículo 44 , que establece el derecho a la cultura; el artículo 105 b), que contempla el acceso de los ciudadanos a los archivos y registros administrativos, aún pendiente de desarrollo normativo; y el artículo 149.1.27, que delimita las competencias entre el Estado y las Comunidades Autónomas en materia de Prensa, reservándose aquél las normas básicas, y que ha propiciado ya un desarrollo normativo por parte de algunas Comunidades Autónomas.

En cuanto a la normativa de desarrollo, se plantea el problema teóri$c o$, que en nuestro país adquiere especiales dimensiones en el presente caso, de la conveniencia o no de su existencia, a tenor de lo establecido en el artículo 53 de la Constitución. Por un lado, es cierto que la libertad de expresión y el derecho de información son derechos de aplicación directa que no requieren, necesariamente, un desarrollo normativo posterior, el cual, en caso de producirse, ha de ser realizado a través de una ley orgánica, de conformidad con lo establecido en el artículo 81, que, además, deberá respetar el contenido esencial de estos derechos y libertades.

${ }^{29}$ Cfr., a este respecto, J. M. Desantes: Teoria y régimen jurídico de la documentación, Eudema, Madrid 1987. 
Por otro lado, se plantea también la conveniencia o no de un desarrollo normativo de los derechos fundamentales. Como es sabido, la teoria liberal clásica se mostraba contraria a este desarrollo, hablando incluso del carácter ilegislable de los derechos naturales. El Proyecto de Constitución de la I República española de 1873, al proclamar que los derechos son naturales y superiores a toda legislación positiva, «sin que ningún poder tenga facultades para cohibirlos ni ley ninguna autoridad para mermarlos», es un ejemplo significativo de ello. Hoy día, aún parece tener cierta vigencia entre nosotros esta teoría liberal, especialmente en relación con determinados derechos y libertades, poniéndose de manifiesto que cualquier regulación de los mismos supondría una restricción o limitación de sus condiciones de ejercicio, resultando, por tanto, mucho más adecuada la ausencia de un desarrollo normativo, máxime cuando su simple reconocimiento constitucional les convierte en derechos directamente aplicables.

Esta concepción, aplicada al régimen de la Prensa, vendría a recoger la máxima, ya establecida por el propio Friedrich Austerlitz, coautor de la Ley de Prensa austriaca de 1922, de que la mejor Ley de Prensa es la que no existe. Sin perjuicio de reconocer la posible fundamentación teórica subyacente a esta concepción, sin embargo hoy dia resulta difícil mantener esta tesis, por dos razones fundamentales ${ }^{30}$ :

a) Una, porque los derechos y libertades constitucionalmente reconocidos si bien, muchos de ellos, son deudores de la concepción liberal, no responden en su totalidad a la misma, pareciendo imposible proclamar su exclusivo carácter de auténticos derechos de libertad. Es decir, el ejercicio efectivo de estos derechos, en unos supuestos más que en otros, parece necesitar la aprobación, con el respeto a los preceptos constitucionales, de determinadas normas organizativas.

b) Otra, relativa ésta al supuesto concreto de la Prensa, porque dada la regulación preconstitucional existente, compuesta fundamentalmente por los restos de la llamada Ley Fraga, así como por la dispersión de la normativa postconstitucional de desarrollo, parece hacerse cada vez más necesario, e incluso resultar totalmente imperativo, un desarrollo normativo de las virtualidades que encierra el artículo 20 de la Constitución, asi como los demás preceptos constitucionales aún faltos de desarrollo, que derogue de una forma categórica la normativa preconstitucional existente y establezca un cierto orden racional, de conformidad con las previsiones constitucionales, ante la disparidad de la normativa existente.

30 Asi lo entiende también F. LOPEZ RAMON: La evolución del régimen jurídico de la libertad de Prensa tras la Constitución de 1978, op. cit. 
$Y$ es que si bien, por un lado, el problema fundamental es determinar la vigencia o no de la normativa preconstitucional, tampoco deja de ser un problema menor la falta de desarrollo de determinados preceptos constitucionales (fundamentalmente, los artículos 18.4, 20.1, d), y 105, b).

En efecto, por referirnos sólo a las disposiciones más importantes, y sin entrar en el análisis de las normas reglamentarias ${ }^{31}$, puede afirmarse que el régimen jurídico de la Prensa en nuestro país, aparte de los aspectos aún vigentes de la Ley Fraga, se encuentra en disposiciones tales como la Ley 29/1984, de 2 de agosto, por la que se regula la concesión de ayudas a empresas periodísticas y agencias informativas, derogada de forma parcial en diferentes ocasiones, como luego veremos, a través de diversas leyes presupuestarias; la Ley Orgánica 2/1984, de 26 de marzo, Reguladora del Derecho de Rectificación; la Ley Orgánica 4/1981, de 21 de junio, Reguladora de los Estados de Alarma, de Excepción y de Sitio; la Ley 33/1988, de 11 de noviembre, General de Publicidad; la Ley 22/1987, de 11 de noviembre, de Propiedad Intelectual, etc. Y ello, sin olvidar determinadas leyes de carácter preconstitucional, como la Ley 8/1968, de 5 de abril, sobre Secretos Oficiales, modificada por la Ley 48/1978, de 7 de octubre, y la Ley 9/1975, de 12 de marzo, del Libro, así como determinadas leyes postconstitucionales que inciden, aunque sea de forma parcial, en determinados aspectos del régimen jurídico de la Prensa, entre las cuales podríamos mencionar la Ley Orgánica 7/1980, de 5 de julio, de Libertad Religiosa; la Ley Orgánica 5/1985, de 19 de junio, de Régimen Electoral General; Ley 26/ 1984, de 19 de julio, de Defensa de Consumidores y Usuarios; Ley 1/1991, de 7 de enero, Reguladora del Derecho a la Información de los Trabajadores y un largo etcétera.

\section{b) La vigencia de la Ley de Prensa e Imprenta de 1966}

No se trata ahora de analizar el contenido y significado de la Ley de 18 de marzo de 1966, la cual, bajo ninguna perspectiva, puede ser considerada como un desarrollo normativo del artículo 20 de la Constitución, sino únicamente poner de relieve cuáles de sus preceptos se encuentran en vigor, dado que nunca ha sido derogada totalmente de forma expresa ${ }^{32}$.

${ }^{31}$ Un análisis riguroso del régimen jurídico de la información en nuestro pais puede verse en J. M. DESANTES: «EI ordenamiento jurídico informativo en España», en la obra colectiva Informe sobre la información: España 1990, op. cit., pp. 9 y ss., muchas de cuyas conclusiones haremos nuestras.

${ }_{32}$ Sin duda alguna, el trabajo fundamental a este respecto es el de C. SoRIA: "La Ley de Prensa de 1966. Los restos del naufragio", Revista Periodistas, núm. 35, julio 1990, cuyos planteamientos haremos nuestros. Cfr., asimismo, E. Gomez-REINo y E. GaRCIA LlOVET: Legislación básica del derecho a la información, Tecnos, Madrid 1985, asi como los estudios anteriormente citados de J. M. DESANTES, LOPEZ RAMÓN Y SOUVIRÓN. 
A la hora de abordar este análisis, pueden adoptarse diferentes perspectivas metodológicas. Así, el propio DESANTES, en el Dictamen elaborado en 1982, establecía los siguientes presupuestos metodológicos ${ }^{33}$ :

a) Normas derogadas por ser contrarias al derecho a la información o a su libre ejercicio y, por tanto, al artículo 20 de la Constitución.

b) Normas derogadas por oponerse a determinaciones constitucionales.

c) Normas vigentes por ser favorables al derecho a la información.

d) Normas vigentes por ser normas técnicas indiferentes a la esencia del derecho a la información.

e) Normas vigentes que, aunque no realicen plenamente el derecho a la información, son preferibles al vacio legal que lo contradiria.

Sin perjuicio de reconocer el carácter exhaustivo de estos criterios, también podría procederse a una simplificación de los mismos, distinguiendo al respecto entre:

1. Preceptos que han sido derogados expresamente por una normativa posterior, y entre los cuales se encontrarían los aspectos más sustanciales de la propia Ley.

2. Preceptos que deben entenderse derogados por su oposición a los preceptos constitucionales, en función de lo establecido en la Disposición derogatoria tercera de la Constitución.

3. Preceptos que continúan manteniendo su vigencia, haya habido o no al respecto una declaración jurisprudencial expresa.

Finalmente, también puede seguirse otro criterio metodológico, consistente en analizar los grandes contenidos de la Ley de Prensa, precisando

33 Así lo pone de relieve C. SoRIA: «La Ley de Prensa de 1966. Los restos del naufragio», op. cit., p. 13. 
al respecto qué preceptos se encuentran o no derogados y por qué razón. Quizá este criterio sea el más adecuado a la finalidad del presente estudio.

$Y$ es que todos estos problemas se plantean porque no ha habido una derogación expresa de la Ley de 1966, sino únicamente derogaciones parciales, las cuales, en principio, no plantean problemas especiales. La cuestión hay que enfocarla desde lo establecido en la Disposición derogatoria tercera de la Constitución: «Asimismo, quedan derogadas cuantas disposiciones se opongan a lo establecido en esta Constitución». Ciertamente, no se trata de analizar la problemática inherente a la derogación, ni tampoco los pronunciamientos constitucionales existentes en torno a cuestiones tales como la diferencia entre derogación e inconstitucionalidad sobrevenida, la competencia de los Tribunales ordinarios y del Tribunal Constitucional, el problema de la derogación sin necesidad de declaración, la eficacia directa de la derogación... ${ }^{34}$. Baste recordar únicamente lo establecido por la sentencia del Tribunal Constitucional 1/1982, de 28 de enero: «Para que opere la derogación de la Disposición tercera de la Constitución sobre una ley, la disconformidad de ésta ha de darse en términos de oposición con la Constitución, y sólo podrá declararse cuando su incompatibilidad con la norma suprema resulte indudable por ser imposible interpretarla conforme a la Constitución». Es decir, el Tribunal antes de proceder a reconocer la existencia de una norma derogada acudirá al principio de interpretación conforme a la Constitución, en cuya problemática pormenorizada nos está vedado entrar en estos momentos. $Y$, como ahora veremos, así ha sucedido con determinados preceptos de la Ley de Prensa.

Junto a estos problemas generales de la derogación de la Ley de 1966, habría que referirse al tema de aquellos preceptos que, aun estando formalmente vigentes, sin embargo son normas que han caído en desuso ${ }^{35}$, lo cual es claramente revelador de la aceptación que hoy día tiene entre nosotros esta ley preconstitucional.

Por ello, el derogar de forma expresa la Ley de Prensa parece convertirse en una tarea urgente que no admite más plazos ni demoras. Incluso, pudiera ser conveniente la derogación simple de la misma, sin ne-

${ }^{34}$ Cfr., con carácter general, los comentarios a la Disposición tercera efectuados por J. L. Peñaranda Ramos en la obra colectiva Comentarios a las leyes políticas, Edersa, 1988, vol. XII, especialmente pp. 671 y ss. Cfr., asimismo, S. VARELA y M. Satrústegul: "Constitución nueva y leyes viejas", Revista de Derecho Político, núm. 4, pp. 59 y ss.; y M. ARAGÓN: «Dos cuestiones interesantes de nuestra jurisprudencia constitucional, control de las leyes anteriores y de la jurisprudencia", dentro del colectivo El Tribunal Constitucional, IEF, vol. I, pp. 557 y ss.

${ }^{35}$ A este respecto, J. M. DESANTES: El ordenamiento jurídico informativo en España, cit., pone como ejemplo de preceptos no derogados pero que la Administración no aplica por haber caído en desuso los artículos 66 a 72 de la Ley, referentes a la problemática de la responsabilidad y de las sanciones. 
cesidad de proceder a la elaboración de una nueva norma que desarrolle los contenidos constitucionales del artículo 20 y demás preceptos aún faltos de desarrollo normativo, impidiéndose de este modo la existencia de una legislación asistemática y falta de coherencia.

$Y$ es que la imagen ofrecida por los «restos» de la Ley Fraga es absolutamente deplorable, pues son «restos fragmentados, asistemáticos, desechos jurídicos, inadecuados al momento actual, que piden a gritos ser clara y definitivamente eliminados por una ley que diga simplemente: queda derogada la Ley de Prensa e Imprenta de 18 de marzo de 1966" ${ }^{36}$.

Una vez efectuadas todas estas consideraciones vamos a proceder a determinar, por grandes áreas temáticas, aquellos preceptos de la Ley de Prensa que se encuentran vigentes o que han sido derogados, de forma expresa o tácita.

\section{De la libertad de prensa e imprenta}

Esta es la rúbrica del capítulo primero de la Ley (arts. 1 a 8 ), que contiene los principios generales que inspiran su contenido. Del análisis del mismo pueden entenderse derogados los siguientes preceptos:

- El artículo 1, por su oposición a la Constitución, en virtud de lo establecido en la Disposición derogatoria tercera.

- El artículo 2, sin duda el más polémico ${ }^{37}$ de la misma, derogado expresamente por el Real Decreto-Ley 24/1977, de 1 de abril.

- El artículo 3, en su referencia a los estados de excepción y de guerra, por oponerse al artículo 55.1 de la Constitución y a la Ley Orgánica 4/1981, de 1 de junio, Reguladora de los estados de Alarma, Excepción y de Sitio.

36 C. Soria: La Ley de Prensa de 1966. Los restos de un naufragio, op. cit., p. 13, para quien los restos de la Ley afectan a cuestiones tales como la figura del director de publicaciones periódicas y agencias informativas, a la profesión periodística, a normas especiales en materia de responsabilidad civil, al deber de publicar noticias de interés general y a informar a los poderes públicos sobre su gestión y actividad.

37 Cfr. E. Gomez Reino: «Las infracciones al artículo 2 de la Ley de Prensa», Revista de Administración Pública, núm. 69, pp. 131 y ss.; y P. CRESPO LARA: El artículo dos, Madrid 1975. 
- El artículo 4, pues la consulta voluntaria es una especie de censura previa no obligatoria, y la Constitución prohibe todo tipo de censura previa. Asimismo, no pueden considerarse vigentes los Decretos 753/1966 y 754/1966, de 31 de mayo, que desarrollaban esta consulta voluntaria.

- El artículo 5, de forma parcial, en relación con el deber especial en relación con los monopolios, pues otorga a la Administración unas facultades discrecionales, incompatibles con el artículo 20 de la Constitución.

Por su parte, pueden considerarse como preceptos vigentes, siempre que se interpreten de conformidad con la Constitución, los siguientes:

- El artículo 3, en su inciso primero, pues la prohibición de censura previa está garantizada constitucionalmente.

- El artículo 6, pues la obligación de insertar informaciones de interés general no parece oponerse a la Constitución, siendo expresamente recogido por el artículo 2 de la LO. 4/1981, de 1 de junio, y por el artículo 16 de la Ley 10/1988, de 3 de mayo, Reguladora de la Televisión Privada.

- El artículo 7, en sus dos párrafos, siempre que se interprete que el deber de información se extiende a todos los poderes públicos, lo cual implica que el desarrollo de este precepto a través del Decreto 750/1966, de 31 de marzo, debe entenderse derogado.

- El artículo 8, siempre que se interprete de acuerdo con la organización administrativa vigente.

\section{De los impresos y publicaciones}

Dentro del capítulo II, artículos 9 a 15, deben entenderse como derogados los siguientes preceptos:

- El artículo 12, que regula el depósito previo de medios informativos, por ser una forma de censura previa. Así lo ha reconocido nuestra propia jurisprudencia constitucional en su sentencia 52/ 1981, de 17 de junio, que extendió esta derogación al artículo 64.2. En consecuencia, debe entenderse también derogada la nor- 
mativa de desarrollo, como son los Decretos $752 / 1966$ y $755 / 1966$, ambos de 31 de marzo, así como las Órdenes de 9 de junio y 30 de septiembre de 1971 .

- El artículo 13, como consecuencia de la inexistencia del depósito previo, siendo el Código Penal la norma tipificadora del delito de difusión de impresos clandestinos.

- El artículo 14, cuya razón de ser aparece íntimamente unida a los dos preceptos anteriores.

Por su parte, pueden considerarse como preceptos no derogados y, por tanto, vigentes, los siguientes:

- El artículo 9, que establece una definición legal de impreso.

- El artículo 10, relativo a las clases de impresos y su diferenciación en publicaciones unitarias y periódicas. No obstante, el desarrollo del precepto, realizado a través del Decreto 743/1966, de 31 de marzo, modificado por el Real Decreto 3471/1977, de 16 de diciembre, que, a su vez, se desarroltó por las Órdenes de 5 de septiembre de 1978 y 21 de mayo de 1975, debe entenderse derogado por oposición a la Constitución.

- El artículo 11, que regula el llamado «pie de imprenta», así como su desarrollo a través del Decreto 751/1966, de 31 de marzo.

- El artículo 15, que se remite a un Estatuto especial en materia de publicaciones infantiles. No obstante, el desarrollo de este precepto, efectuado a través del Decreto 195/1967, de 19 de enero, regulador del Estatuto de Publicaciones Infantiles y Juveniles, debe entenderse derogado por las medidas restrictivas que establece y que resultan incompatibles con el artículo 20 de la Constitución.

\section{Las empresas periodísticas, agencias informativas y empresas importadoras de publicaciones}

Los capítulos III (arts. 16 a 25), IV (arts. 26 a 32), VI (arts. 43 a 49) y VIII (arts. 55 a 57), deben entenderse derogados en su totalidad por la Ley 29/1984, de 2 de agosto, por la que se regula la concesión de ayudas a empresas periodísticas y agencias informativas, Ley que, a su vez, como 
veremos en el capitulo siguiente, ha sido derogada a través de diferentes leyes presupuestarias ${ }^{38}$.

En consecuencia con ello, también debe entenderse derogada la diversa normativa de desarrollo, entre la cual habría que mencionar el Decreto 749/1966, de 31 de marzo, por el cual se regula la inscripción en el Registro de Empresas Periodísticas; el Decreto 742/1966, de 31 de marzo, que regulaba la inscripción en el Registro de Agencias Informativas, así como la Orden de 1 de septiembre de 1966, que concedió a la Agencia Efe, S. A., la exclusiva en la distribución de noticias provenientes de agencias extranjeras, y los Decretos 744/1966 y 747/1966, ambos de 31 de marzo, relativos a la difusión de publicaciones editadas en el extranjero y a la acreditación e inscripción de corresponsales de medios informativos extranjeros en nuestro pais.

\section{La profesión periodística y los directores de las publicaciones periódicas}

El capítulo $V$ de la Ley, artículos 33 a 42 , constituye uno de los ejes centrales de la misma, no habiéndose producido una derogación expresa de su contenido. En consecuencia, hay que proceder a una interpretación conforme a la Constitución, de la cual hay que entender derogados los siguientes preceptos:

- El artículo 33 ha de entenderse derogado de forma parcial, especialmente en lo referente al principio de colegiación, en las referencias a la organización sindical preconstitucional y en la existencia de un Jurado de ética profesional.

- El artículo 36.1 , en sus apartados 2,3 y 4 , por ser contrario al artículo 20 de la Constitución la exigencia de una responsabilidad administrativa por los mensajes difundidos.

- El artículo 39.1 parece oponerse, por razones anteriormente expuestas, al contenido esencial del artículo 20.

38 Algunos sectores doctrinales (F. LÓPEZ RAMON: El régimen jurídico de la Prensa..., op. cit.), entiende que la regulación de estas cuestiones se encuentra en vigor, planteándose únicamente la vigencia de determinados preceptos, como son los artículos $16,17.1,18.3$ y 20.1 , que impiden a los extranjeros y españoles residentes fuera de nuestro pais la participación en empresas periodísticas. 
Por el contrario, deben considerarse vigentes los demás preceptos de este capítulo, es decir:

- El artículo 33, en lo referente al principio de profesionalidad, aunque no la inscripción en un Registro Oficial dependiente de la Administración Pública.

- Los artículos 34, 35, 37 y 38, por no oponerse a los contenidos constitucionales. A este respecto, la sentencia del Tribunal Constitucional 171/1990, de 12 de noviembre, ha declarado expresamente en vigor el articulo 37.

- Los artículos 39.2, 40, 41 y 42, por idéntica razón. Asimismo, la sentencia anteriormente citada ha reconocido expresamente la vigencia del artículo 40.1 .

\section{Las empresas editoriales}

El capítulo VII de la Ley de Prensa, artículos 50 a 54, debe considerarse enteramente vigente, así como el Decreto 748/1966, de 31 de marzo, relativo al registro de empresas editoriales, aunque debe procurarse su articulación con otras disposiciones, como son la Ley 9/1975, de 12 de marzo, del Libro, y el régimen de inversiones extranjeras y organización administrativa.

\section{Los derechos de réplica y rectificación}

El capitulo IX de la Ley de Prensa, artículos 58 a 62, está derogado expresamente por la Ley Orgánica $2 / 1984$, de 26 de marzo, que regula el derecho de rectificación y a la que posteriormente también aludiremos. Naturalmente, esta derogación afecta también a los Decretos 745/1966 y $746 / 1966$, ambos de 31 de marzo, reguladores de los derechos de rectificación y réplica.

\section{La responsabilidad y las sanciones}

El último capítulo de la Ley, articulos 63 a 72 , y que constituye también un elemento nuclear de la misma, exige, a falta de una derogación expresa del mismo, un proceso de interpretación conforme a la Constitu- 
ción, en virtud del cual deben entenderse derogados los siguientes preceptos:

- El artículo 64.2, que había sido derogado expresamente por el Real Decreto-Ley 24/1977, de 1 de abril, y por la Ley 62/1978, de 26 de diciembre, en virtud de las cuales se procedió a la modificación de su redacción, configurándose un total de cinco apartados. Los cuatro últimos fueron derogados por la última disposición citada y el apartado $A$ ) debe entenderse derogado tácitamente por la Constitución, tal y como lo ha establecido la ya citada sentencia del Tribunal Constitucional 52/1983, de 17 de junio.

- El artículo 65.3, por oponerse a los contenidos constitucionales ya analizados.

- El último inciso del artículo 66, por suponer una violación del principio non bis in idem.

- El artículo 67, a) y b), como consecuencia de la derogación de los artículos 1 y 2 y capítulo VIII de la Ley de Prensa, antes referidos.

- El artículo 68.1, b), por resultar contrario a la Constitución la exigencia de responsabilidad administrativa por los mensajes difundidos.

- En el artículo 69 deben considerarse expresamente derogadas todas aquellas sanciones consistentes en suspensión, pues así lo establece el ya citado Real Decreto-Ley 24/1977, de 1 de abril. Asimismo, deben considerarse derogados el Decreto de 4 de agosto de 1952 y las Órdenes de 22 de octubre de 1952 y de 29 de noviembre de 1956, en virtud de lo establecido en la citada Ley 62/1978, de 26 de diciembre.

En consecuencia con lo anteriormente expuesto, deben entenderse como vigentes los siguientes preceptos:

- Los artículos 63 y 64.1, por no oponerse a los contenidos constitucionales.

- El artículo 65.1, 2 y 4, por idéntica razón ${ }^{39}$.

${ }^{39}$ A este respecto, el Auto $1243 / 1988$, de 14 de noviembre, no reconoció la pretendida derogación del artículo 65.2 alegada por el recurrente. 
- El artículo 66, a excepción de su último inciso.

- El artículo 67, c), por no oponerse a los contenidos constitucionales.

- El artículo 68.1, a), con excepción de la referencia al artículo 62, que ha sido expresamente derogado, y el artículo 68.2, por no oponerse tampoco a los contenidos constitucionales.

- El artículo 69, únicamente en lo referente a las sanciones que consistan en multas.

- Los artículos 70,71 y 72 , por no oponerse a los contenidos constitucionales, y siempre que los dos primeros preceptos se interpreten de conformidad con la actual organización administrativa existente.

\section{EL CONTENIDO DE LA LIBERTAD DE PRENSA}

No se trata, en las presentes páginas, de analizar todo el contenido del derecho a la información a través de los medios impresos, sino únicamente referirnos a una serie de cuestiones que consideramos fundamentales para el estudio de la problemática de la Prensa.

Se trata, en suma, de partir de una serie de premisas, como son la autonomía del derecho a la información respecto de la libertad de expresión, tal y como ha sido configurado por nuestra jurisprudencia constitucional, sin olvidar aquellas posturas doctrinales que no admiten esta concepción dualista y que proclaman la existencia de un único derecho fundamental, el derecho a la información, del cual forma parte la libertad de expresión. En virtud de ello, y teniendo en cuenta que la autonomía del derecho a la información afecta tanto a su fundamento, como a la problemática de sus sujetos, objeto y medios de ejercicio, vamos a analizar, referido únicamente a la Prensa, una serie de cuestiones, entre las que destacan las siguientes:

a) Los sujetos de la información

Como ya hemos visto, el artículo 20.1, d), habla del derecho «a comunicar o recibir libremente información veraz», lo cual, a tenor de lo es- 
tablecido por nuestra jurisprudencia constitucional, implicaba la protección de la información errónea y, a su vez, la existencia de una pluralidad de sujetos informativos ${ }^{40}$.

Siguiendo a C. SORIA ${ }^{41}$, hemos de señalar que a la hora de determinar a quién pertenece la información es posible distinguir diferentes etapas históricas, en las cuales es posible diferenciar una pluralidad de sujetos.

Asi, una primera etapa, que coincide con la época de las Monarquías absolutas y la aparición de la primera Prensa periódica en Europa Occidental, tendría al Rey como titular del derecho a la información. Es la época en la que para editar era necesario la concesión de una licencia real, que se otorgaba como un privilegio discrecionalmente por parte del Monarca, el cual detentaba un auténtico control político sobre la publicación.

Una segunda etapa, que se produce a finales del siglo XVIII, viene condicionada por la concepción liberal de la libertad de expresión y de la libertad de empresa. Es la etapa empresarista de la información, en la cual la libertad de Prensa se concretiza en una libertad para el empresario, que es quien decide todo acerca de la información, es decir, la empresa informativa se configura como una auténtica empresa privada, cuya finalidad fundamental es la obtención de beneficios.

A finales del siglo $\mathrm{xIx}$ surge la tercera etapa, que podemos calificar como la etapa profesionalista de la información. Es la época del apogeo de la profesión periodística, produciéndose una importante revolución tecnológica en la información y apareciendo los primeros estatutos de la profesión periodistica, los Códigos deontológicos, el sistema de los Consejos de Prensa etc...

Finalmente, habría que hablar de la etapa universalista de la información, en la cual ésta pertenece al público. La información se configura como un auténtico derecho fundamental, que consiste en la facultad de investigar, difundir y recibir información, existiendo, como ya pusiera de relieve entre nosotros el propio DESANTES ${ }^{42}$, y asi lo recogiera nuestra

40 A este respecto, M. A. Garcia Herrera: Estado democrático y libertad de expresión, op. cit., configura la información veraz como un límite interno. Cfr., asimismo, J. Vilas NogueiRa: «El derecho a la información mendaz (Algunas consideraciones sobre la jurisprudencia constitucional acerca de la libertad de información)", Revista Jurídica de Castilla-La Mancha, núms. 3 y 4, pp. 635 y ss.

${ }^{41}$ C. Soria SaIz: La información pertenece al público. Más allá del capitalismo informativo, Universidad de Navarra, Pamplona 1987. Cfr., asimismo, E. Novoa MONREal: Derecho a la vida privada y libertad de información. Un conflicto de derechos, Editorial Siglo XXI, Madrid 1979.

${ }_{42}$ J. M. DeSANTES: “El público y la información», Ponencia a la XXXIV Semana Social de España, Segovia 1986. 
jurisprudencia constitucional, una especie de mandato informativo, en virtud del cual el público es el mandante y los informadores los mandatarios. En esta etapa, la empresa informativa adquiere una nueva dimensión, dejando de ser una típica empresa mercantil, planteándose otros problemas a los que iremos aludiendo.

Nuestra jurisprudencia constitucional, como ya hemos apuntado, ha abordado también la problemática de los sujetos de la información desde una doble perspectiva. Por un lado, reconociendo, aunque el titular del derecho sea el público, el papel preponderante de los profesionales de la información, que se plasma jurídicamente en el carácter preferente de este derecho fundamental cuando es ejercido por los periodistas. $Y$, por otro, contemplando el ejercicio del derecho a la información por determinados sectores del público, fundamentalmente los sujetos a una relación funcionarial o contractual.

Así, la ya reiterada sentencia $6 / 1981$, de 16 de marzo, tras señalar que «la preservación de esta comunicación pública libre... exige la garantía de ciertos derechos fundamentales comunes a todos los ciudadanos... pero también una especial consideración a los medios que aseguran la comunicación social y, en razón de ello, a quienes profesionalmente la sirven", concluye: "Son estos derechos, derechos de libertad frente al poder y comunes a todos los ciudadanos. Quienes hacen profesión de la expresión de ideas u opiniones o de la comunicación de información, los ejercen con mayor frecuencia que el resto de sus conciudadanos, pero no deriva de ello ningún privilegio y desde luego no el de transformar en su favor, lo que para el común de los ciudadanos es derécho de libertad, en un derecho de prestación que los legitime para exigir de los poderes públicos la creación o el mantenimiento de medios de comunicación a través de los cuales puedan expresar sus opiniones o comunicar información». Así pues, en esta primera aproximación jurisprudencial, el ejercicio del derecho a la información por los profesionales de ésta, no altera la naturaleza de este derecho, convirtiéndolo en un derecho de prestación, sino que continúa conservando su condición de auténtico derecho de libertad, siendo los periodistas «actores destacados en el proceso de la libre comunicación social... que pueden invocar derechos cuya configuración concreta es mandato que la Constitución (art. 20.1, d), in fine) da al legislador”.

Un paso importante en esta configuración jurisprudencial se va a producir en la sentencia 30/1982, de 1 de junio, relativa a la acreditación de Diario 16 en el proceso del $23 \mathrm{~F}$, en la cual, tras analizar el significado del principio de publicidad de los juicios, reconocido en el artículo 120.1 de la Constitución, señala que ésta sólo puede hacerse efectiva con la presencia de los medios de comunicación social, que por ser una especie de «intermediario natural», tienen un derecho preferente atribuido en virtud de la función que cumplen. Es decir, la sentencia da un paso más justificando su carácter preferente cuando es ejercida por los profesionales de la información, pues éstos ejercen «un papel de intermediario natural desem- 
peñado por los medios de comunicación entre la noticia y cuantos no están, así, en condiciones de conocerla directamente" ${ }^{43}$.

Esta idea del carácter preferente del derecho a la información cuando es ejercida por los profesionales de la misma, se pone mucho más de relieve en la sentencia 168/1986, de 22 de diciembre, relativa al caso de la revista Tiempo, en la cual se señala que «los sujetos de este derecho son no sólo los titulares del órgano o medio difusor de la información o los profesionales del periodismo o quien, aun sin serlo, comunican una información a través de tales medios, sino, primordialmente, la colectividad y cada uno de sus miembros». Ahora bien, tras esta reiteración de la doctrina anterior, la sentencia reconoce que la Constitución tiene en cuenta «la posición jurídica subjetiva de quienes comunican la información», pero también protege "la facultad de cada persona y de la entera colectividad de acceder libremente al conocimiento, transmitido por los medios de comunicación, de los hechos de relevancia realmente acaecidos".

Desde la segunda perspectiva, es decir poniendo el acento en el ejercicio del derecho a la información por parte de determinados colectivos, nuestra jurisprudencia constitucional ha reconocido la existencia de determinados limites, derivados principalmente de las relaciones contractuales o funcionariales y del propio principio de lealtad, recordando en todo caso que, a tenor de lo establecido en el artículo 7 del Código Civil, los derechos habrán de ejercitarse conforme a las exigencias de la buena fe ${ }^{44}$.

Nuestro ordenamiento jurídico, en materia de sujetos del derecho a la información ${ }^{45}$, contiene una regulación que viene determinada por las propias caracteristicas del ordenamiento jurídico informativo. A este respecto, podemos distinguir entre la consideración del público como sujeto universal y la problemática de los profesionales de la información.

Por lo que se refiere a la primera cuestión, hay que señalar que nuestro ordenamiento jurídico le ha prestado una menor atención. Pense-

43 Análogo significado hay que predicar de la sentencia 105/1983, de 23 de noviembre, cuando señala que «el sujeto primero de este derecho es la colectividad y cada uno de sus miembros, cuyo interés es el soporte final de este derecho, del que es asimismo sujeto, órgano o instrumento, el profesional del periodismo, puesto que a él concierne la búsqueda de la información y su posterior transmisión".

${ }^{44}$ Cfr., entre otras, las sentencias 120/1983, de 15 de diciembre, referente al ejercicio de la libertad de expresión en las relaciones laborales; 171/1985, de 6 de marzo; 88/1985, de 19 de julio; 6/1988, de 21 de enero; así como el Auto 1121/ 1988 , de 10 de octubre.

${ }_{45}$ Cfr., a este respecto, J. M. DESANTES: «El ordenamiento juridico informativo en España», op. cit., especialmente pp. 12 y ss. La última manifestación de nuestro ordenamiento jurídico informativo en este tema es la ya citada Ley $1 / 1991$, de 7 de febrero, sobre el derecho de información de los trabajadores, actualmente recurrida ante el Tribunal Constitucional. 
mos, a modo de ejemplo, en el significado del artículo 15 de la Ley de Prensa de 1966 y en su desarrollo, a través del Estatuto de Publicaciones Infantiles y Juveniles, que nosotros hemos considerado derogado. Pero, sin duda alguna, la participación más activa del público en el ejercicio del derecho a la información se efectúa a través del ejercicio del derecho de rectificación, sobre el cual volveremos más adelante.

Mayor importancia parece haber prestado nuestro ordenamiento jurídico al sujeto profesional, es decir, al periodista. Recordemos, a este respecto, que el artículo 33 de la Ley de Prensa preveía la aprobación, por Decreto, de un Estatuto de la Profesión Periodística, que fue aprobado por Decreto 744/1967, de 13 de abril, siendo posteriormente modificado en diversas ocasiones a través de los Decretos 900/1972, de 16 de marzo; 1978/ 1973, de 5 de julio, y los Reales Decretos 1926/1976, de 16 de julio, y 3148/ 1976 , de 3 de diciembre. La vigencia o no de esta normativa debe analizarse de acuerdo con los mismos postulados que hemos utilizado en torno a la Ley de Prensa, conservándose únicamente aquellos aspectos técnicos que no contradigan la Constitución. Por todo ello, hay que proclamar la inexistencia de una normativa especifica que se adecue al texto constitucional, resultando, por tanto, aplicables determinadas normas de carácter general, como son la Ley de Asociaciones de 1964, gracias a la cual se constituyó la Federación de Asociaciones de la Prensa en España, o la Ley de Colegios Profesionales, que ha tenido su desarrollo especifico en algunas Comunidades Autónomas, o al propio Estatuto de los Trabajadores, que es la norma que regula la vinculación del periodista con el medio informativo.

Ciertamente, la problemática de los sujetos de la información afecta a otra serie de cuestiones, como pudiera ser el tema de las empresas informativas, que nosotros vamos a abordar de forma separada. No obstante, si quisiéramos referirnos a la problemática de la cláusula de conciencia y al secreto profesional de los periodistas, constitucionalizado en el artículo 20.1, d), y que aún está pendiente del correspondiente desarrollo legislativo.

En principio, hay que efectuar una distinción entre ambos supuestos. La cláusula de conciencia es la posibilidad que se reconoce al profesional de la información de resolver su contrato de trabajo, sin que ello le ocasione perjuicios económicos, cuando se produzca un cambio en la orientación ideológica de la empresa en que trabaja. El reconocimiento de la cláusula de conciencia es consecuencia directa de la superación de la etapa empresarista de la información, que configuraba a las empresas informativas como auténticas empresas mercantiles. Es, pues, una «cláusula legal, implícita en el contrato de trabajo periodístico, según el cual, en determinados supuestos que la Ley tipifica en relación con la conciencia del informador, los efectos económicos de la extinción de la relación laboral periodística 
producidos por voluntad unilateral del trabajador equivalen a los del despido por voluntad del empleador" ${ }^{46}$.

Normalmente suele considerarse a la Ley francesa de 1935 como la primera norma reguladora de la cláusula de conciencia, señalándose que su existencia parece exigir dos requisitos. Uno, objetivo, consistente en el cambio de la orientación ideológica del periódico, y otro, subjetivo, que se manifiesta en que dicho cambio afecta a la conciencia del informador. El tema no es ajeno al surgimiento de los primeros Códigos deontológicos, pudiendo afirmarse que en la actualidad parecen haberse agotado todas sus virtualidades y no pareciendo necesaria la constitucionalización de la mismas $^{47}$.

Una mayor importancia plantea hoy día la problemática del secreto profesional de los periodistas. A este respecto, el debate doctrinal se centra en la idea de si nos encontramos ante un auténtico derecho fundamental o, por el contrario, ante un deber constitucional. Ciertamente, la regulación que efectúa nuestra Constitución supone una novedad que no tiene parangón en el Derecho Comparado, debiendo destacarse las diferencias existentes entre la regulación que efectúa el artículos 20.1 , d), que es la que ahora nos interesa, y la realizada por el artículo 24.2, cuando se constitucionaliza el secreto profesional. Sin duda alguna, estamos ante dos supuestos diferentes y lo importante es afirmar que, a tenor de lo establecido en el artículo $20.1, d$ ), nos encontramos ante un auténtico derecho fundamental.

Asimismo, se plantea el problema del contenido y límites de este derecho. A este respecto, hay que señalar que, si bien estamos en presencia de un auténtico derecho, éste posee un cierto carácter instrumental, que implica que nuestra Constitución lo configura como un derecho limitado, siendo el bien jurídico protegido, no la intimidad, como sucede con el secreto profesional del artículo 24.2, ni tampoco la protección de la noticia, sino la identidad de la fuente de información, es decir, el derecho al secreto profesional es el derecho a silenciar las fuentes de información ${ }^{48}$.

46 J. M. Desantes, A. Nieto y M. Urabayen: La cláusula de conciencia, Eunsa, Pamplona 1978, p. 117.

${ }^{47}$ Asi lo entiende C. SorIA: «Qué es la cláusula de conciencia», Nuestro Tiempo, núm. 394, abril 1987, quien proclama que la regulación efectuada por la Constitución española debe entenderse ya superada, pues su existencia es propia de épocas históricas ya ampliamente superadas, tendentes a ir más allá de la simple configuración liberal de la libertad de expresión.

${ }_{48}$ Seguimos en toda esta cuestión los planteamientos efectuados por A. Fernandez-MiRAnda: El secreto profesional de los informadores, Tecnos, Madrid 1990, quien no considera el contenido de la Ley de Secretos Oficiales como un límite al secreto profesional, sino a las libertades informativas, poniendo, asimismo, de relieve la inexistencia de un consenso para proceder al desarrollo normativo del artículo $20.1, d)$. 
$Y$ es que como ya pusiera de relieve en 1947 el propio Consejo de Europa, "el secreto profesional es el derecho del periodista a negarse a revelar la identidad del autor de la información a su empresa, a terceros y a las autoridades públicas y judiciales " ${ }^{49}$.

b) El objeto de la información

Bajo este epígrafe vamos a referirnos a una serie de cuestiones puntuales, entre las cuales merecen destacarse las siguientes:

1) ¿Existe un deber de informar?

Como ya vimos en su momento, la existencia de un derecho fundamental a la información, no implica la correlativa existencia de una obligación de informar. Recordemos, a este respecto, el Auto 560/1983, de 16 de diciembre, en el cual se afirma que el derecho a obtener libremente información «no supone obviamente la correlativa obligación de toda persona física o juridica de suministrar información de cualquier tipo a todo el que la solicite», pues esta obligación únicamente se producirá en los casos y supuestos establecidos por la Ley.

Desde este planteamiento inicial, parece congruente poder afirmar que la existencia de un deber de informar por parte de los poderes públicos únicamente puede ser exigible cuando se considere como contenido esencial de un derecho fundamental o cuando exista una previsión normativa al respecto. Pensemos, a modo de ejemplo, en las especialidades que pueden corresponder a determinados sujetos informativos, como pueden ser los parlamentarios, en el ejercicio de las funciones de control político y siempre de acuerdo con las previsiones constitucionales y reglamentarias establecidas.

Prescindiendo del ámbito parlamentario, hay que recordar la vigencia del artículo 7 de la Ley de Prensa e Imprenta de 1966, que consagraba el derecho a obtener información oficial, en la forma que legalmente se determine. A este respecto, también hay que mencionar, dentro de la nor-

49 Citado por J. TERRÓN MONTERo: «Libertad de expresión y Constitución», Documentación Administrativa, núm. 187, Madrid 1980, p. 223, nota 28 . Sobre la problemática del secreto profesional, cfr., asimismo, J. Rigo VALLBONA: El secreto profesional y los periodistas, Bosch, Barcelona 1988; E. Gomez REINo: «El secreto profesional de los periodistas", Revista de Administración Pública, núms. 100-102, vol. I; J. M. DESANTES: “Eficacia actual del secreto profesional informativo", $A E D E$, núm. 12, 1986; J. M. MichAVILA NúÑEZ: «El artículo 24 de la Constitución y el derecho al secreto profesional: una visión unitaria de la institución», Revista Española de Derecho Administrativo, núm. 56, 1987, pp. 537 y ss. 
mativa preconstitucional, las materias reservadas por la Ley de Secretos Oficiales, de 7 de octubre de 1978, que restringe el ámbito de las materias que podian ser excluidas de la publicidad, y que permite la existencia de un control jurisdiccional sobre las decisiones adoptadas por el Consejo de Ministros o la Junta de Jefes del Estado Mayor.

Una mayor importancia parece presentar lo dispuesto en el artículo 105, b), de la Constitución, cuando establece que la Ley regulará «el acceso de los ciudadanos a los archivos y registros administrativos, salvo en lo que afecte a la seguridad y defensa del Estado, la averiguación de los delitos y la intimidad de las personas". Como ya hemos señalado, este derecho de acceso por parte de todos los ciudadanos aún no ha recibido su correspondiente desarrollo normativo, encontrando su antecedente más importante en los Estados Unidos y su «Freedom of Information Act», de $1966{ }^{50}$, encerrando una serie de potencialidades que exigen cada vez más su rápida puesta en práctica.

\section{2) La prohibición de censura previa}

Como ya vimos, la concepción liberal de la libertad de expresión era consustancial a la prohibición de toda censura previa. No obstante, ésta no siempre se logró en nuestro constitucionalismo histórico, pese a los pronunciamientos constitucionales existentes. Recordemos, a modo de ejemplo, la situación en nuestra II República y la reinstauración de la censura previa en la Ley de Policía de Imprenta de 22 de abril de $1938^{51}$.

Nuestro ordenamiento jurídico, como no podía ser de otro modo, prohibe cualquier tipo de censura previa (art. 20.2). El problema consiste en determinar si se permite alguna modalidad de intervención que pudiera presentar alguno de los caracteres propios de la censura previa. Ya vimos cómo determinados preceptos de la Ley de Prensa de 1966 deberian entenderse derogados por contemplar alguna modalidad de censura previa. El mismo criterio debemos aplicar a lo dispuesto en el artículo 193 del Código Penal, en lo que a la expresión «fuera de los casos permitidos por las leyes" se refiere.

$Y$ es que nuestra jurisprudencia constitucional ha sido contundente al respecto, no permitiendo, de conformidad con los contenidos constitucionales, ningún tipo de censura como pudiera ser el depósito previo.

${ }^{50}$ Así lo pone de relieve J. M. Souvirón: Notas para una ley sobre la información, op. cit., pp. 35 y 36.

51 Cfr., a este respecto, J. A. VALLES: «La censura gubernativa de Prensa en España (1914-1931)", Revista de Estudios Políticos, núm. 21. 
Así, la sentencia 52/1983, de 17 de junio, establece: «La Constitución española dispone la eliminación de todos los tipos imaginables de censura previa, aun los más débiles y sutiles, que tengan por efecto no ya el impedimento o la prohibición, sino la simple restricción de los derechos de su artículo 20.1, de lo que se infiere que los artículos 12 y 64 de la Ley de Prensa e Imprenta constituyen un tipo de censura previa restrictivo de los derechos del citado artículo, por lo que han de estimarse derogados por la Constitución española». Y es que el Tribunal Constitucional no considera lo mismo el depósito previo que el depósito legal, que pretendía introducir, a imitación del modelo establecido en la Ley Fraga, la Ley catalana 11/ 1982, de 13 de enero.

En otra ocasión, en la sentencia 13/1985, de 31 de enero, dictada con motivo del caso Última Hora, de Palma de Mallorca, el Tribunal se remite a la sentencia anterior para definir la censura previa, señalando que «por tal puede entenderse cualquier medida limitativa de la elaboración o difusión de una obra del espíritu, especialmente al hacerla depender del previo examen oficial de su contenido". En consecuencia con ello, la sentencia señala que se exige un ánimo o propósito de censura, pues el llamado «previo examen oficial», «implica la finalidad de enjuiciar la obra en cuestión con arreglo a unos valores abstractos y restrictivos de la libertad, de manera que se otorgue el placet a la publicación de la obra que se acomode a ellos a juicio del censor y se le niegue en caso contrario». Es decir, se exige el ánimo o propósito censor.

No obstante, y pese a la contundencia de nuestro ordenamiento constitucional, y de la doctrina establecida por nuestra jurisprudencia constitucional, desde determinados sectores doctrinales ${ }^{52}$ se ha puesto de manifiesto cómo determinados desarrollos normativos pueden ser considerados como una manifestación de la quiebra de la prohibición de la censura previa.

3) El derecho de rectificación

Anteriormente hemos apuntado que el ejercicio del derecho de rectificación podía ser considerado como una de las manifestaciones más importantes de la consideración del público como sujeto de la información.

52 Así lo entiende J. M. Desantes: «De la libertad de expresión al derecho a la información", Persona y Derecho, vol. 24, 1991, pp. 23 y ss., quien menciona expresamente determinados contenidos de la Ley 16/1988, de 29 de julio, de disciplina e intervención de las entidades de crédito, y de la Ley 34/1988, de 11 de noviembre, General de Publicidad. 
Nuestro ordenamiento jurídico referente a esta cuestión viene determinado por la Ley Orgánica 2/1984, de 26 de marzo, que habia derogado expresamente el capítulo IX de la Ley de Prensa e Imprenta, que establecía la distinción entre el derecho de réplica y el derecho de rectificación, distinción que se fundamentaba en los titulares de su ejercicio (personas o Administración). En la actualidad esta dualidad ha desaparecido, pudiendo el derecho ser ejercido por cualquier persona jurídica o natural, afectando su contenido a la rectificación, por cualquier medio de comunicación social, de aquellos hechos que le aludan y que considere inexactos y cuya divulgación pueda causarle perjuicio ${ }^{53}$.

Así pues, el objeto de la rectificación son los hechos inexactos y no los juicios y opiniones que se hubieran podido expresar. El director de la publicación viene obligado a difundir la rectificación dentro de los tres días siguientes al de su recepción, con una relevancia semejante al de la publicación difamatoria. En caso de que no se produzca esta rectificación, la Ley prevé un procedimiento sumario, en virtud del cual el perjudicado ejercerá su acción dentro de los siete días hábiles siguientes, ante el juez de Primera Instancia, el cual, una vez admitida a trámite la demanda, convocará a las partes a juicio verbal, que se celebrará dentro de los siete días siguientes al de la petición. El juicio se tramitará conforme a lo establecido en la Ley de Enjuiciamiento Civil para los juicios verbales, con una serie de especialidades - las previstas en el artículo 6 de la Ley-, que son expresión clara y contundente de su carácter sumario. La decisión del juez no es susceptible de recurso alguno.

Sobre el significado del derecho de rectificación ya se ha pronunciado nuestra jurisprudencia. Asi, por lo que se refiere a la jurisprudencia ordinaria, habria que citar la sentencia del Tribunal Supremo de 23 de marzo de 1987, en la cual se afirma que «el ejercicio del derecho de rectificación constituye una mera facultad u opción conferida por la Ley a quien se considere perjudicado por la divulgación de informaciones difundidas por los medios de publicidad», concluyendo que su ejercicio no supone la exclusión de otros procedimientos, como pudiera ser el ejercicio de las correspondientes acciones civiles y/o penales.

En cuanto a nuestra jurisprudencia constitucional, habría que citar dos importantes sentencias. Por un lado, la sentencia 35/1983, de 11 de mayo, en la cual se establece que el derecho de rectificación tiene "un

53 Sobre la problemática general del derecho de rectificación, cfr. C. MoLINERO: Teoria y fuentes del derecho a la información, op. cit., pp. 157 y ss.; T. GoNZÁlez BallesteRos: El derecho de réplica y rectificación en Prensa, Radio y Televisión; F. Sobrao: Información y derecho de réplica, Madrid 1974; M. Carrillo: "Libertad de expresión y derecho de rectificación en la Constitución española de 1978 (Comentario a la Ley Orgánica 2/84, de 26 de marzo), Revista de Derecho Político, núm. 23, pp. 39 y ss. 
carácter puramente instrumental en cuanto que su finalidad se agota en la rectificación de informaciones publicadas por los medios de comunicación y que aquel que solicite la rectificación considera lesivas de derechos propios». Junto a este carácter instrumental, la sentencia determina el objetivo del mismo, indicando que "sólo puede ejercerse con referencia a datos de hecho (incluso juicios de valor atribuidos a terceras personas), pero no frente a opiniones, cuya responsabilidad asume quien las difunde». $Y$, finalmente, señala que el trámite para su ejercicio debe ser sumario, a fin de garantizar la rápida publicación de la rectificación, debiendo «ser regulado y ejercitado en términos que ni frustren su finalidad ni lesionen tampoco el derecho que también la Constitución garantiza a comunicar y recibir libremente».

Mayor importancia tiene la ya reiterada sentencia 168/1986, de 22 de diciembre, que ha sido objeto de importantes criticas doctrinales ${ }^{54}$ por la configuración que efectúa del derecho de rectificación.

En efecto, la sentencia comienza afirmando que el derecho de rectificación tiene una finalidad y eficacia diferentes del ejercicio de las acciones civiles y penales, pues «es sólo un medio de que dispone la persona aludida para prevenir o evitar el perjuicio que una determinada información pueda irrogarle en su honor o en cualesquiera otros derechos o intereses legítimos, cuando considera que los hechos lesivos mencionados en la misma no son exactos. Esta finalidad preventiva - que es independiente de la reparación del daño causado por la difusión de una información que se revela objetivamente inexacta - quedaría frustrada en muchos casos por la demora en la rectificación pretendida».

Posteriormente, tras reconocer que «se satisface este derecho mediante la publicación integra y gratuita de la rectificación, referida exclusivamente a los hechos de la información difundida", analiza la sumariedad del procedimiento judicial y la posición del juez, señalando que éste no está obligado "a una indagación completa de la veracidad de los hechos difundidos o publicados», cabiendo la posibilidad de la difusión de un escrito de rectificación que pudiera no revelarse ajustado a la verdad. Con ello, el derecho de rectificación parece desnaturalizarse, convirtiéndose únicamente en un derecho de protesta de la persona afectada, cuya subjetividad se convierte en elemento determinante. Es decir, más que un de-

${ }^{54}$ Cfr. C. SORIA: «El derecho de rectificación (Comentarios a la sentencia del Tribunal Constitucional de 22 de diciembre de 1986)", Revista Documentación de las Ciencias de la Información, núm. 12, 1989, pp. 27 y ss., quien señala que la sentencia «transforma el derecho de rectificación en un derecho de acceso por alusiones", pues no se refiere a la falsedad de los hechos sino a la apreciación subjetiva de la persona aludida. Cfr., asimismo, C. CHINCHILLA: "Sobre el derecho de rectificación (Comentario a la STC 168/1986, de 22 de diciembre)", Poder Judicial, núm. $6,1987$. 
recho de rectificación se constitucionaliza un derecho al disentimiento. En consecuencia con esta concepción, la sentencia proclama la posibilidad, por parte del medio de comunicación, de ratificarse en la información inicial, negando, asimismo, la lesión del derecho reconocido en el artículo 20.1, d).

\section{c) La regulación de los medios informativos}

Aunque esta cuestión podría haber sido abordada, desde un punto de vista metodológico, dentro del apartado relativo a los sujetos del derecho a la información, hemos creído conveniente, por su importancia, proceder a un análisis por separado de su problemática.

En nuestro ordenamiento jurídico no existe una regulación unitaria aplicable a todos los medios de información, sino una normativa individualizada en virtud del soporte que canaliza el mensaje informativo. Por lo que se refiere a la Prensa, objeto único de nuestro estudio, parece conveniente efectuar las siguientes precisiones ${ }^{55}$.

Como ya pusimos de relieve, el contenido esencial del derecho a la información comprende el derecho a crear los medios materiales para su ejercicio, derecho éste, que en el tema de la Prensa, no presenta las limitaciones que en otros medios, como pudiera ser el caso de la radiodifusión o de la televisión. Es decir, la problemática de las empresas informativas encuentra su fundamento constitucional en el propio artículo 20 , y no en el artículo 38, que reconoce el derecho a la libertad de empresa, como se sostenía desde otras posiciones doctrinales. Y es que nuestra Constitución parece haber superado la concepción liberal, que configuraba a las mismas como auténticas empresas privadas, cuya finalidad esencial no era el ejercicio de la libertad de expresión, sino la obtención de lucro, no diferenciándose sustancialmente de las demás empresas mercantiles ${ }^{56}$.

También pusimos de relieve cómo, pese a la existencia de alguna discrepancia doctrinal, la regulación efectuada por la Ley de Prensa había sido derogada por la Ley de 1984, relativa a ayudas a empresas periodísticas y agencias informativas, la cual, a su vez, habia sido reiteradamente

55 F. CONESA SÁnchez: La libertad de empresa periodística, Eunsa, Pamplona 1978, quien habla de la Ilamada «libertad interna de la Prensa».

${ }_{56}$ No obstante, el Auto de la Sala Tercera del Tribunal Supremo, de 22 de julio de 1981, proclama contundentemente que "la gestión y explotación de una cadena privada de televisión afecta primordialmente al derecho de la libre empresa en relación con los medios de comunicación". 
derogada por medio de leyes presupuestarias, planteándose el problema de cuál es la normativa aplicable al caso.

Prescindiendo del análisis de una serie de medidas administrativas relativas a su creación, estructura y funcionamiento ${ }^{57}$, hemos de señalar que nuestra Constitución, en su artículo 20.5, establece que «sólo podrá acordarse el secuestro de publicaciones, grabaciones y otros medios de información en virtud de resolución judicial'", cuestión que se remite a lo establecido en el artículo 21.1 de la LO. 4/1981, en virtud de la cual se autoriza el secuestro gubernativo de publicaciones en los estados de excepción y de sitio. $Y$ es que, como ha señalado nuestra jurisprudencia constitucional en la sentencia 144/1987, de 23 de septiembre, relativa al precintado de emisoras, en el caso de «Radio Canfali», "no cabe calificar de secuestro una actuación que no se dirige contra publicaciones o grabaciones o cualquier otro soporte de una comunicación determinada, esto es, de un mensaje concreto, sino contra el instrumento capaz de difundir».

Como es sabido, la Ley de Prensa distinguia entre impresos periódicos, cuya regulación es desarrollada por el Decreto 743/1966, de 31 de marzo, modificado parcialmente por el Real Decreto 2089/1984, de 14 de noviembre, y medios unitarios, en cuya regulación jurídica hay que tener en cuenta lo dispuesto por la Ley 9/1975, de 12 de marzo, del Libro, y demás normas de desarrollo ${ }^{58}$.

Pero sin duda alguna, el problema principal que se plantea, dadas las premisas anteriormente apuntadas, es si se debe establecer o no un régimen especial para las empresas informativas ${ }^{59}$. Indudablemente, y de acuerdo con nuestra posición doctrinal, hay que afirmar que existe un fundamento constitucional al respecto, pues las empresas informativas no son simples empresas mercantiles, ya que su razón de ser no es el artículo 38 de la Constitución, sino el propio artículo 20. Es decir, desde esta perspectiva, parece tener fundamento constitucional la existencia de un régimen especial para las empresas periodísticas, que incluso pudiera llegar a ser

" Cfr., a este respecto, J. SALAS: Registro de empresas periodísticas y editoriales (Régimen de inscripciones y de cancelaciones), Sevilla 1975.

${ }_{58}$ Sobre esta cuestión, cfr. J. M. DESANTES: El ordenamiento juridico informativo en España, op. cit., pp. 19 y ss.

${ }_{59}$ Cfr. las diferentes posturas doctrinales mantenidas por F. LOPEZ RAMÓN: La revolución del régimen jurídico de la libertad de Prensa tras la Constitución de 1978, op. cit., quien afirma que «cuando la Constitución ha querido unir los aspectos empresariales al reconocimiento de uno de los derechos fundamentales de la sección primera del capítulo segundo, lo ha hecho expresamente, como sucede en el artículo 27, donde se reconoce junto al derecho a la educación y la libertad de enseñanza, la libertad de creación de centros docentes" (p. 402); J. M. SouvIRón: Notas para una ley sobre la información, op. cit.; y F. J. BASTIDA: La libertad de antena. El derecho a crear televisión, op. cit., cuyo planteamiento doctrinal seguimos nosotros. 
considerado como un desarrollo de las previsiones del artículo 20. Ahora bien, desde otra perspectiva, también puede considerarse que la posible existencia de este régimen especial pudiera ser interpretado como una modalidad o intento de control gubernamental de las mismas.

Dentro de esta segunda línea argumental es donde hay que encuadrar las reacciones que se producen por parte de la mayoría de los sectores informativos, cuando, desde sede gubernamental, se intenta la adopción de medidas especiales en relación con las empresas informativas. Ante esta situación, los afectados parecen preferir el apoyo constitucional del artículo 38, recordando que el registro especial de empresas periodísticas había sido derogado en 1984, y que éstas ya figuran, como cualquier otra empresa, en el Registro Mercantil correspondiente.

\section{d) Las ayudas a la Prensa}

Como ya pusimos de relieve, la publicación de la Ley 29/1984, de 2 de agosto, así como el Real Decreto 2089/1984, de 14 de septiembre, a través del cual se produce el desarrollo de la misma, supuso la derogación de determinados capitulos de la Ley de Prensa e Imprenta de 1966, en concreto de los capitulos III, IV, VI y VIII.

La problemática de las ayudas a la Prensa parece encontrar su apoyo. constitucional en el artículo 20 , si bien hay que recordar que la sentencia de 16 de marzo de 1981 rechazó la obligación de ayuda económica del Estado como una exigencia derivada de este precepto constitucional, que configura auténticos derechos de libertad y no de prestación, y, más específicamente, en el artículo 149.1.27, que delimita las competencias entre el Estado y las Comunidades Autónomas en materia de Prensa, pues como ha señalado nuestra jurisprudencia constitucional en la sentencia 64/1989, de 6 de abril, las ayudas son un medio para garantizar el derecho a la información. En función de todo ello, hay que afirmar que el régimen de ayudas a la Prensa ha experimentado una evolución en nuestro ordenamiento jurídico a la que es preciso referirse.

$Y$ es que la subvención estatal a la Prensa es susceptible de ser enfocada desde una pluridad de facetas ${ }^{60}$. Así, atendiendo a un planteamiento puramente económico se plantea la cuestión de si la existencia de una subvención pública debe o no obligar al editor a dejar que los grupos políticos significativos puedan expresarse en su periódico, obligando a

${ }_{60}$ Este planteamiento entre las ayudas estatales a la Prensa y el necesario mantenimiento del pluralismo informativo puede verse en F. J. BASTIDA: La libertad de antena. El derecho a crear la televisión, op cit., pp. 276 y 277. 
aquél a una especie de pluralismo interno. $Y$, desde otro punto de vista, el sistema de ayudas estatales, además de permitir a todos los ciudadanos la recepción de noticias a un precio asequible, debe procurar también el soporte de los costes económicos de la rotativa, impidiendo que por motivos puramente económicos no se garantice el pluralismo informativo.

Como es sabido, la Ley de 1984 distinguía entre ayudas directas, consistentes en las transferencias de fondos en función de la difusión, el consumo de papel de Prensa y la reconversión tecnológica, y ayudas indirectas, consistentes en beneficios de carácter tributario, crediticio, postal, de distribución, de comunicación y otros análogos.

Para poder acogerse a estas ayudas, las empresas periodisticas y agencias informativas debian reunir una serie de requisitos, entre los cuales destacaba la necesidad de figurar inscritas en un Registro administrativo de empresas periodisticas y agencias informativas, a los exclusivos efectos de la concesión de ayudas, Registro que aparecía minuciosamente regulado en los artículos 7 y ss. del Real Decreto 2089/1984, de 14 de septiembre.

Ahora bien, ambas disposiciones, la Ley y el Real Decreto de 1984, que regulaban el régimen de ayudas a la Prensa, han sido objeto de derogaciones parciales a través de diferentes leyes presupuestarias.

a) En primer lugar, la Ley $37 / 1988$, de 28 de diciembre, por la que se aprueban los Presupuestos Generales para 1989, procedió a la derogación de los artículos 2.1, a); 2.2, 3; 4, b); 5 y Disposición adicional segunda de la Ley, así como los artículos 4, b); 9, c), apartado tercero, y artículos 15 a 42 del Real Decreto de 1984.

b) Posteriormente, la Ley $4 / 1990$, de 29 de junio, por la que se aprueban los Presupuestos Generales del Estado para 1990, en su Disposición derogatoria cuarta, deroga expresamente el apartado a) del punto 1 del artículo 2; el apartado f) del artículo 4 y el artículo 6 de la Ley de 1984, así como los correspondientes preceptos de desarrollo establecidos en el Real Decreto citado.

c) Finalmente, la Ley $31 / 1990$, de 27 de diciembre, por la que se aprueban los Presupuestos Generales del Estado para 1991, en su Disposición transitoria segunda, declara derogados los artículos $1.2 .1, b$ ); 4, a), c), d), e) y g); 7 y 8; Disposición adicional primera y Disposición final de la Ley de 1984, así como los preceptos de desarrollo complementarios.

Es decir, en un primer momento, se suprimieron las ayudas directas por difusión y por consumo de papel. Posteriormente, en junio de 1990 , se procedió a la supresión de las ayudas directas correspondientes a recon- 
versión tecnológica y, finalmente, se ha procedido a la liquidación de todo el sistema de ayudas a la Prensa, quedando ésta privada también de las ayudas indirectas a través de los beneficios tributarios, crediticios y postales, lo que a la postre va a suponer para la misma su sometimiento a las reglas del libre mercado.

Esta supresión de las ayudas a la Prensa ha merecido diversas reacciones por parte de ésta, que van desde la consideración de las mismas como una manifestación del control político gubernamental, que no se ha atrevido a adoptar otras manifestaciones anunciadas, hasta entender su supresión como un correctivo político destinado a determinados medios de difusión que eran contrarios a la política gubernamental.

Realmente, la situación en los países de la Comunidad Económica Europea permite la constatación de todo tipo de situaciones, pudiendo distinguir, a tal efecto, entre:

a) Paises que carecen de todo tipo de ayudas, directas e indirectas: Dinamarca, Grecia, Irlanda y, ahora, España

b) Países que únicamente disponen de un sistema de ayudas indirectas: Inglaterra y Alemania.

c) Países que poseen ambos tipos de ayudas, directas e indirectas: Francia, Italia, Portugal, Holanda y Luxemburgo.

d) Países con sistema de ayuda directa, pero no indirecta: Bélgica.

En suma, se trata de una opción del legislador, susceptible de diversas y contradictorias interpretaciones. Pero no debemos olvidar que la concesión de ayudas a la Prensa cuenta con un apoyo constitucional indudable, como ha recordado la sentencia 191/1990, de 29 de noviembre, reiterando la doctrina establecida en decisiones anteriores.

\section{LAS GARANTÍAS DE LA LIBERTAD DE PRENSA}

\section{a) Introducción}

El derecho a la información, en cuanto derecho fundamental que es, está dotado del sistema de garantías, judiciales y extrajudiciales, previsto 
en los artículos 53 y ss. de nuestra Norma Fundamental, y sobre cuyo significado general no parece oportuno pronunciarse en estos momentos. Ahora bien, antes de referirnos al sistema de garantías y a la problemática de los límites en torno a la libertad de Prensa, parece oportuno recordar una serie de premisas ya analizadas en páginas anteriores.

Por un lado, hemos de recordar cuanto dijimos en torno a la naturaleza de la libertad de expresión y del derecho a la información, tanto por lo que a su carácter de derechos de libertad se refiere ${ }^{61}$, como por lo que, especialmente, a su carácter preferente atañe. Preferencia, recordémoslo, que no tiene, sobre todo en el supuesto de colisión con otros derechos fundamentales, como es el caso del derecho al honor del artículo 18, un carácter absoluto, sino que se encuentra sujeta a un juicio de ponderación en los términos establecidos por nuestra jurisprudencia constitucional, aún no definitivamente consolidada al respecto.

Por otro lado, hemos de tener en cuenta que la regulación efectuada por la Ley de Prensa e Imprenta de 1966, no reconocía una auténtica libertad de Prensa, sino que establecía una serie de importantes controles, que hoy dia deben entenderse derogados. Entre éstos, habria que mencionar especialmente el control de acceso a la profesión periodistica, establecido por el artículo 33 y su desarrollo posterior a través del Estatuto de 1967; el control administrativo de la información; las importantes potestades sancionadoras atribuidas a la Administración por los artículos 66 y ss., posteriormente modificadas por el Real Decreto-Ley de 1 de abril de 1977, que, a su vez, deroga el famoso artículo 2 y establece una nueva redacción del artículo 165 bis del Código Penal y de los artículos 64.2 y 69 de la Ley Fraga y que, a su vez, fue derogado por la Ley de 26 de diciembre de 1978, suprimiéndose las facultades administrativas para decretar el secuestro.

No obstante, nuestro ordenamiento juridico permite el secuestro de publicaciones cuando se produzca la declaración del estado de excepción en los términos del artículo 21.1 de la LO. 4/1981, de 1 de junio, no cabiendo, ni en este caso, ningún tipo de censura previa, y siempre y cuando la autorización del Congreso de los Diputados comprenda la suspensión del artículo 20, de conformidad con lo establecido en el artículo 55 de la Constitución.

Todas estas consideraciones nos conducen al análisis de lo establecido en el artículo 20.4: «Estas libertades tienen su limite en el respeto a los derechos reconocidos en este título, en los preceptos de las leyes que

${ }^{61}$ Cfr., a este respecto J. J. SolozABAL: «Aspectos constitucionales de la libertad de expresión y del derecho a la información», Revista Española de Derecho Constitucional, núm. 23, 1988, donde se establece que es dogmáticamente inadmisible su condición de derechos de prestación (p. 147), razón por la cual no se puede hablar de un deber de ayuda por parte del Estado. 
los desarrollan y, especialmente, en el derecho al honor, a la intimidad, a la propia imagen y a la protección de la juventud y de la infancia». Este precepto ha recibido una fuerte crítica doctrinal ${ }^{62}$, que ha puesto de manifiesto las insuficiencias del mismo, pues, por un lado, no contemplaba todos los límites posibles al ejercicio de estas libertades $y$, por otro, su contenido es reiterativo, contemplándose como límites tanto auténticos derechos fundamentales como bienes constitucionalmente protegidos, lo cual debe conllevar a una diferente naturaleza de los mismos, $y$, finalmente, produciéndose una especie de subordinación de la libertad de expresión a través de unas cláusulas generales amenazadoras del contenido esencial del propio derecho.

Todo ello ha supuesto la necesidad de que nuestra jurisprudencia constitucional haya tenido que pronunciarse en numerosas ocasiones sobre el significado del artículo 20.4, ocasiones en las que se ha limitado a analizar casuísticamente el problema de los límites del derecho a la información, sin elaborar una teoría general de los mismos, que aún no se encuentra consolidada entre nosotros ${ }^{63}$. Como ejemplo de esta postura habria que mencionar las siguientes decisiones jurisprudenciales.

En primer lugar, la sentencia 62/1982, de 15 de octubre, relativa al caso $A$ ver, la cual parte del principio de que toda restricción a los derechos fundamentales ha de estar justificada, centrándose en la problemática de la moral pública como límite al ejercicio de los mismos, reconocida en diferentes Declaraciones internacionales. Protección de la moral, dentro de la cual hay que considerar incluida la protección de la juventud y de la infancia, que ha de entenderse, como asi se establece en el artículo 10.2 del Convenio de Roma, y de conformidad con la interpretación efectuada por el Tribunal Europeo de Derechos Humanos, con la moral propia de una sociedad democrática, debiendo procederse a su aplicación con la finalidad para la cual ha sido prevista.

62 Cfr., a este respecto, M. A. Garcia Herrera: Estado democrático y libertad de expresión, op. cit.; C. SORIA: El derecho a la información en la Constitución española, op. cit., J. M. DESANTES: De la libertad de expresión al derecho a la información, op. cit.; M. CARRILlo: Los límites a la libertad de Prensa en la Constitución española de 1978, PPU, Barcelona 1987; P. BARRoso AsENJo: Límites constitucionales del derecho a la información. Ed. Mitre, Barcelona 1984, y un larguísimo etcétera.

${ }_{63}$ Cfr., a este respecto, las sentencias $153 / 1985$ y $51 / 1989$, así como los Autos $413 / 1983,171 / 1985,737 / 1987,1325 / 1987,1121 / 1988,199 / 1989$, y un largo etcétera. Todo ello, sin olvidar, como ya hemos apuntado, que la propia exigencia constitucional de la veracidad informativa debe considerarse no como un principio programático, sino como un componente normativo dotado de plena eficacia jurídica. Así lo pone de manifiesto M. CarRiLlo: «Derecho a la información y veracidad informativa», Revista Española de Derecho Constitucional, núm. 25, 1988. 
Por su parte, el Auto 216/1984, de 4 de abril, señala que el problema de los límites del artículo 20.4 queda, en buena medida, remitido a las leyes de desarrollo, como pudiera ser el propio Código Penal, encontrándonos, en consecuencia, ante una cuestión de mera legalidad ordinaria, cuya competencia corresponde a los Tribunales ordinarios. Ya volveremos sobre esta cuestión.

Finalmente, habría que citar la sentencia 159/1986, de 16 de diciembre, relativa al caso Egin, en la cual, tras señalar que los derechos fundamentales no son absolutos, como tampoco lo son los límites a los mismos, proclama que existe un régimen de concurrencia normativa y no un régimen de exclusión, «de tal modo que tanto las normas que regulan la libertad como las que establecen límites a su ejercicio vienen a ser igualmente vinculantes y actuar recíprocamente. Como resultado de esta interacción, la fuerza expansiva de todo derecho fundamental restringe, por su parte, el alcance de las normas limitadoras que actúan sobre el mismo; de ahí la exigencia de que los límites de los derechos fundamentales hayan de ser interpretados con criterios restrictivos y en el sentido más favorable a la eficacia y a la esencia de tales derechos".

Todo ello, concluye la sentencia, porque si bien los derechos fundamentales son «elementos esenciales de un ordenamiento objetivo de la comunidad nacional», hay que proclamar que «tanto las normas de libertad como las llamadas normas limitadoras se integran en único ordenamiento inspirado por los mismos principios en el que, en último término, resulta ficticia la contraposición entre el interés particular subyacente a los primeros y el interés público que, en ciertos supuestos, aconseja su restricción. Antes al contrario, tanto los derechos individuales como sus limitaciones, en cuanto éstas derivan del respeto a la Ley y a los derechos de los demás, son igualmente considerados por el artículo 10.1 de la Constítución como fundamento del orden político y de la paz social».

Como anteriormente apuntábamos, nuestra jurisprudencia constitucional o bien se limita a analizar casuísticamente el problema, reproduciendo en buena medida la doctrina del Tribunal Europeo de Derechos Humanos, o bien se sitúa en el terreno de los principios generales, a veces, como acabamos de ver, con ciertas contradicciones entre la naturaleza de las Ilamadas normas de libertad y las normas limitadoras de la misma, no habiéndose aún construido una teoría coherente de los límites del derecho de la información.

\section{b) Garantías de orden civil}

La protección civil de la libertad de Prensa estuvo, en un principio, garantizada por lo dispuesto en los artículos 1092 y 1902 del Código 
Civil ${ }^{64}$. Posteriormente, y ante la falta de un desarrollo normativo del artículo 53.2 de la Constitución, pues no puede tener esta consideración, como asi expresamente lo ha declarado nuestra jurisprudencia constitucional, la Ley 26/1987, de 26 de diciembre, de Protección Jurisdiccional de los Derechos Fundamentales de la Persona, se aprobó la Ley Orgánica 1/1982, de 5 de mayo, de Protección Civil del Derecho al Honor, a la Intimidad Personal y Familiar y a la propia Imagen, que ha sido objeto de una importante critica doctrinal ${ }^{65}$, poniendo de manifiesto tanto su carácter pretencioso como las insuficiencias de su contenido, pero que, a la postre, ha supuesto un indudable apogeo de las acciones civiles frente a las acciones penales, las cuales eran preponderantes hasta 1982.

Prescindiendo de la problemática inherente al derecho al honor, a la intimidad y a la propia imagen, que aparecen concebidos como derechos fundamentales irrenunciables, inalienables e imprescriptibles, por lo que se refiere al ámbito de nuestro estudio, la problemática más importante afecta a la consideración de las llamadas intromisiones ilegítimas, a tenor de lo establecido en el artículo 7 de la Ley, especialmente en los supuestos contemplados en los apartados $3,4,6$ y 7 . Sin perjuicio de señalar que algunas de ellas adolecen de una auténtica falta de realismo, consecuencia de ese carácter pretencioso a que anteriormente nos referiamos, hay que proclamar que todas ellas deben ser interpretadas restrictivamente.

Por lo que se refiere a su sistema de garantías, el artículo 9 de la Ley, tras reconocer que la tutela judicial podrá recabarse por las vías procesales ordinarias o por el procedimiento - aún pendiente de desarrollopreferente y sumario del artículo 53.2, señala que ésta comprenderá «la adopción de todas las medidas necesarias para poner fin a la intromisión ilegítima de que se trate y restablecer al perjudicado en el pleno disfrute de sus derechos, asi como para impedir o prevenir intromisiones ulteriores». Asimismo, tras reconocer la posibilidad de medidas cuatelares, entre

${ }^{64}$ El artículo 1092 dispone: «Las obligaciones civiles que nazcan de los delitos o faltas se regirán por las disposiciones del Código Penal». Por su parte, el artículo 1902 establece: «El que por acción u omisión causa daño a otro, interviniendo culpa o negligencia, está obligado a reparar el daño causado".

${ }_{65}$ Cfr., a este respecto, S. MuÑoz MACHADO: Libertad de Prensa y procesos por difamación, Ariel, Barcelona 1987; I. Berdugo: Honor y libertad de expresión, Tecnos, Madrid 1987; E. Estrada Alonso: El derecho al honor en la LO. 1/1982, de 5 de mayo, Civitas, Madrid 1988; J. VIDAL MARTINEZ: El derecho a la intimidad en la Ley Orgánica de 5 de mayo de 1982, Montecorvo, Madrid 1984; C. SoRiA: "Uso y abuso de la protección civil del honor", Cuenta y Razón, núm. 34, febrero 1988; Cabello Mohedano: «El artículo 20.1 de la Constitución, ¿una nueva configuración de la exceptio veritatis», en Poder Judicial, núm. 8, 1987, pp. 35 y ss., y un largo etcétera. Posteriormente, el artículo 2.2 de la Ley fue modificado por la LO. 3/1985, de 29 de mayo, cuya clara inconstitucionalidad fue reconocida por nuestro Tribunal Constitucional. 
las cuales se encuentra el derecho a replicar, establece los posibles criterios de valoración de la indemnización, que se extenderá al daño moral.

Aunque el análisis del contenido de la Ley de 1982 escapa a las pretensiones del presente estudio, centrándose más bien en la problemática del derecho al honor, es necesario recordar alguna de la numerosa jurisprudencia que ha generado su aplicación.

A este respecto, siguiendo las orientaciones de MUÑOZ MACHADO ${ }^{66}$, parece que nuestra jurisprudencia civil, de igual modo que luego veremos sucede con la jurisprudencia penal, en el uso de las técnicas jurídicas que maneja no parecen garantizar suficientemente el desarrollo de los contenidos constitucionales, quizá porque aún no está suficientemente consolidado entre nosotros el contenido constitucional del derecho a la información. A este respecto, cuestiones tales como la diferenciación entre lo público y lo privado, el hecho de que no es preciso que la noticia sea completamente exacta, la imposibilidad de exigencia de una prueba completa de la verdad, la necesidad de que la rectificación tenga un valor atenuante y la imposibilidad de exigir la prueba de la verdad sobre las opiniones, deben convertirse en criterios que han de inspirar la actuación de nuestros Tribunales ordinarios.

\section{c) Garantias de orden penal}

Como es sabido, las garantias penales parecen gozar de una especial prevalencia en relación con otro tipo de garantías. Por lo que se refiere a nuestro estudio, nuestro ordenamiento positivo contempla una regulación no excesivamente sistemática, que ha sido objeto de diferentes modificaciones a través de la Leyes Orgánicas 4/1980, de 21 de mayo; 5/1983, de 25 de junio, y 3/1988, de 25 de mayo ${ }^{67}$.

Antes de entrar a analizar diversos contenidos del Código Penal, hay que plantear la cuestión de la relación competencial existente entre los Tribunales ordinarios y el Tribunal Constitucional. Ciertamente, nos encon-

66 S. MuÑoz Machado: Libertad de expresión y procesos por difamación, op. cit., especialmente pp. 46 y ss., donde analiza una serie de sentencias importantes, tanto de los Juzgados de Primera Instancia como del propio Tribunal Supremo. Como ejemplo significativo, cfr., asimismo, la sentencia del Tribunal Supremo de 25 de abril de 1989, relativa al «caso Paquirri»; la de 27 de octubre de 1989, referente a la problemática del resarcimiento de los daños morales, y la de 11 de diciembre de 1989. $Y$ es que, como establece la sentencia del Tribunal Supremo de 23 de marzo de 1987, el derecho al honor "puede verse atacado, lesionado o vulnerado por la divulgación, a través de los medios de comunicación e información, y especialmente los de muy alta audiencia pública, de actos, hechos, noticias... relativos a personas, tanto físicas como sociales, que pueden afectar tanto a su propia estimación, como a su esfera familiar y a su consideración socioprofesional".

${ }_{67}$ Cfr. el planteamiento realizado por F. MuÑoz CondE: El Derecho Penal. 
tramos ante cuestiones de mera legalidad ordinaria que, a priori, parecen exceder de la competencia del Tribunal Constitucional, el cual no debe convertirse en una segunda instancia jurisdiccional penal. No obstante, la diferenciación entre cuestiones de legalidad ordinaria y de relevancia constitucional no es siempre fácil de precisar y nuestro Tribunal, celoso de sus competencias, ha proclamado, desde un principio, que cualquier cuestión que afecte a los derechos fundamentales y de las libertades públicas entra dentro del ámbito de sus competencias. Si a esto añadimos que, en raras ocasiones, nuestra jurisprudencia penal parece haber estado a la altura de las circunstancias, no es de extrañar que el Tribunal haya realizado pronunciamientos como el que contempla la sentencia 104/1986, de 17 de junio: «Dada la evidente perspectiva constitucional del caso, el juez no estaba obligado a otorgar preferencia a uno u otro de los derechos en juego, pero sí estaba obligado ex artículo 53.1 de la Constitución a tomar en consideración la eventual concurrencia en el caso de la libertad de opinión y de la libertad de información a través de la Prensa del periodista cuyo artículo se enjuiciaba. Lo que no pudo es razonar y fallar aplicando e interpretando. exclusivamente los artículos 586, 460 y 570 del Código Penal, sin tener en cuenta, como es obligado, la proyección que sobre ellos tiene la libertad consagrada en el artículo 20 de la Constitución, cuya mención y análisis omite por completo".

Los contenidos penales que inciden en el ámbito de nuestro estudio se encuentran fundamentalmente tipificados en los siguientes artículos del Código Penal:

a) Los artículos 13 y 15, que atribuyen la responsabilidad de los delitos cometidos por medio de la imprenta, el grabado u otra forma de reproducción, a los autores, desapareciendo la responsabilidad de cómplices y encubridores ${ }^{68}$.

b) El artículo 165 bis, que tipifica el impedimento u obstaculización del libre ejercicio de la libertad de expresión y difusión informativa, contemplando, asimismo, la responsabilidad de autores, directores, editores e impresores por la emisión de impresos clandestinos ${ }^{69}$.

c) El artículo 213, que permite al Tribunal decretar el comiso de

Parte especial, Valencia 1988; y por M. Cobo, J. Boix, E. Orts y J. C. CarbonelL: Derecho Penal. Parte especial, Tirant Lo Blanch, Valencia 1990.

${ }_{68}$ Cfr., a este respecto, las sentencias del Tribunal Supremo de 27 de septiembre de 1980, 25 de noviembre de 1988, 12 de noviembre de 1981, 3 de junio de 1983,10 de junio de $1985 .$. de 1982.

69 Cfr., a este respecto, la sentencia del Tribunal Supremo de 23 de febrero 
la imprenta cuando lo estime procedente, decretándolo siempre cuando ésta fuera clandestina.

d) Los artículos 453 a 467, donde se tipifican los delitos contra el honor, especialmente la calumnia y la injuria.

e) Los artículos 240 y ss., donde se tipifica el delito de desacato.

Al igual que sucedía con la problemática de las garantías civiles, hemos de señalar, siguiendo a MUÑOZ MACHADO ${ }^{70}$, que tampoco nuestra jurisprudencia penal parece haber sido consciente de la realidad de los contenidos constitucionales. Esta escasa penetración de los principios constitucionales en la jurisprudencia penal ha sido constatada por nuestra propia jurisprudencia constitucional. Así, en la ya reiterada sentencia 156/ 1986, de 12 de diciembre, relativa al caso Egin, se afirma que «a los órganos judiciales correspondía asumir la interpretación más favorable al derecho fundamental $y$, a sus efectos, sobre las normas penales limitadoras del mismo que, en definitiva, se concretan en el criterio de que el derecho de un profesional del periodismo a informar, así como el de sus lectores a recibir información íntegra y veraz, constituye, en último término, una garantía institucional de carácter objetivo, cuya efectividad exige, en principio, excluir la voluntad delictiva de quien se limita a transmitir sin más la información, aunque ésta, por su contenido, pueda revestir significado penal».

70 S. MUÑOz MACHADO: Libertad de expresión y procesos por difamación, op. cit., especialmente pp. 17 y ss., donde analiza una serie de decisiones judiciales tipo, comprendidas entre los años 1980-1984. 